\title{
Development of a methodology to assess man-made risks in Germany
}

\author{
D. Borst ${ }^{1,2}$, D. Jung ${ }^{1,2}$, S. M. Murshed ${ }^{1,2}$, and U. Werner ${ }^{1,2}$ \\ ${ }^{1}$ University of Karlsruhe (TH), Institute for Finance, Banking and Insurance, 76128 Karlsruhe, Germany \\ ${ }^{2}$ Center for Disaster Management and Risk Reduction Technology (CEDIM), 76128 Karlsruhe, Germany
}

Received: 27 April 2006 - Revised: 11 July 2006 - Accepted: 11 September 2006 - Published: 22 September 2006

\begin{abstract}
Risk is a concept used to describe future potential outcomes of certain actions or events. Within the project "CEDIM - Risk Map Germany - Man-made Hazards" it is intended to develop methods for assessing and mapping the risk due to different human-induced hazards. This is a task that has not been successfully performed for Germany so far. Concepts of catastrophe modelling are employed including the spatial modelling of hazard, the compilation of different kinds of exposed elements, the estimation of their vulnerability and the direct loss potential in terms of human life and health.
\end{abstract}

The paper is divided in two sections: First, an analytic framework for assessing the broad spectrum of humaninduced risks is introduced. This approach is then applied for three important types of human-induced hazards that are representative for a whole class of hazards: Accidents due to nuclear power plants (NPP) or air traffic, and terrorism.

For the analysis of accidents, risk is measured with respect to getting injured or dying when living in certain buffer zones around hazard locations. NPP hazard expert knowledge is used and supplemented with observations on aging effects leading to a proprietary index value for the risk. Air traffic risk is modelled as an area related phenomenon based on available accident statistics leading to an expected value of risk.

Terrorism risk is assessed by the attraction certain elements (like embassies in the case of conventional threats) display in the eye of potential aggressors. For non-conventional targets like football games, a detailed approach measuring their susceptibility to different kinds of attacks within predefined scenarios was developed; this also allows a ranking of attack modes.

Correspondence to: D. Borst

(d.borst@fbv.uka.de)
1 State of the art of mapping man-made risks in Germany

The objective of the paper is to develop a methodology for assessing major man-made risks in Germany based on a spatial analysis of their impacts on people and physical assets. Such an approach is needed for mapping this type of risk alongside with risks related to natural hazards. A map server solution, the "Risk Explorer" (cf. Müller et al., 2006), will show both natural and human-induced hazards, exposures, vulnerabilities, and risks within one viewer system. This is a crucial first step towards the integrated assessment of a multitude of hazards. Such maps are fundamental to risk mitigation and risk management planning at the individual, company, and societal level - but up to date no comprehensive risk maps are publicly available for the whole of Germany. ${ }^{1}$

In 2004, Bundesamt für Bevölkerungsschutz und Katastrophenhilfe (BBK, Federal Office for Civil Protection and Disaster Response) started a project to collect information about the main hazards in each state in order to derive a "Harmonized Hazard Assessment" for Germany. Not all of the federal states are complied, and the incoming reports differed in quantity and detail. The risk analysis of Hessen is considered exemplary and can be accessed via the internet (http://www.nassauischer-feuerwehrverband.de/ Downloads/KatSGefaehrdungsanalyse.pdf [17/07/2006]). It provides some statistics and qualitative descriptions of natural hazards, technological accidents, malicious actions of persons, hysteric behaviour at mass events, and war. It also gives a first idea about the mitigation capacity available to manage these risks. However, none of the hazards mentioned is mapped or assessed in conjunction with others.

\footnotetext{
${ }^{1}$ The hazard maps of insurance companies cover a wide range of natural hazards but do not provide information on human-induced hazards: see, e.g., Munich Re's Natural Hazards Assessment Network (http://mrnathan.munichre.com [17/07/2006]) or Swiss Re's CatNet.
} 
Another approach considered as a pilot study for countrywide risk mapping is the Schutzdatenatlas (Protection Data Atlas: http://www.kfs.uni-kiel.de/ sda/ [17/07/2006]) developed at the Disaster Research Center of the ChristianAlbrechts University of Kiel. This GIS-based platform has been serving as a research tool for the development of methods dedicated to vulnerability analyses. As a starting point, it relies on object data of a county (Ditmarschen) in Northern Germany.

BBK developed DeNIS II - a geo-referenced information system for mapping hazardous objects and events in Germany as well as weather conditions and mitigation resources. It can also integrate remote sensing data and is available both for the federal and the state level and for nongovernmental relief organizations. The general public, however, has to rely on the web-site (http://www.denis.bund.de [17/07/2006]) which provides links to articles and other kind of information from various, mostly scientific, sources. Topics listed range from natural disasters to chemical and nuclear accidents, traffic accidents, terrorism, fire, and explosions. The user is expected to integrate the information provided and to assess his/her risk. The problems resulting from the approach employed for the public website are evident: Nobody - neither layperson nor expert - is able to make up a comprehensive ad hoc-assessment of the risks related to a specific geographic area.

To sum up, there are several lacunae to be filled regarding the mapping of man-made risks in Germany: First of all, more data has to be collected for a harmonized and countrywide hazard assessment as intended by the BBK. Second, this data needs to be collected and analyzed following a standardized approach in order to assure its comparability across various kinds of hazards, exposure, and vulnerability. Public security permitting the information then has to be made available to the public in an intelligible way.

Maps are good instruments for integrating complex geography-related and other data, but there are hardly any approaches for mapping man-made risks on German territory. One exception is the European Union (EU) wide research program ESPON ${ }^{2}$ where partners from various European countries have been conducting research on natural and technological hazards. However, due to the focus on spatial planning responses, a thorough filtering of the research objects was done which reduced the technological hazards considered to a relatively small number including major accident hazards of Nuclear Power Plants (NPP) and chemical plants, air traffic as well as oil processing, transport and storage. "Social hazards" (following the terminology of EEA, 2003:VI) like terrorism or war have not been investigated in detail. ${ }^{3}$ Despite limited access to data on technological

\footnotetext{
${ }^{2}$ European Spatial Planning Observation Network (ESPON): http://www.espon.eu [17/03/2006], cf. Schmidt-Thomé (2006).

${ }^{3}$ Risk consulting companies like Risk Management Solution (RMS) or EQECAT, on the other hand, do offer integrated anal-
}

hazards (Schmidt-Thomé, 2006:65f.), the international consortium was able to construct preliminary synthetical maps regarding hazard, vulnerability, and risk for the EU $27+2$.

We chose to develop our approach based on a generic catastrophe model as used in geographic information systems. It is laid out in Sect. 2. To facilitate a comprehensive assessment of man-made risks and their mapping by means of more standardized data, a detailed typology of man-made risks is presented, too. Additionally, we highlight some general problems in assessing these risks and briefly state the reasons for selecting certain hazards for a detailed consideration within this paper. Section 3 provides an overview of the general methodological approach used for data analysis and visualisation of risks in maps. Section 4 explains in detail our work done for assessing and mapping these risks. According to the project context, only direct loss potentials are assessed for drawing the risk map; at the same time, considerations about individual or societal risk perception have to be disregarded. Section 5 finally provides a short summary and gives an outlook of future research necessities and possibilities. Our analytic framework for risk specific analyses and the mapping of selected man-made risks might serve as a starting point for integrated risk research in this area.

\section{Concept of risk}

2.1 Quantitative approach for assessing and mapping manmade risks

There is a multitude of risk concepts and a large variety of taxonomies defining aspects like hazard, exposure or vulnerability. Renn (2005:114-138) gives an exhaustive overview of the risk terminology currently used in scientific and engineering literature or in documents published by international organizations like the United Nations International Strategy for Disaster Reduction (UN/ISDR). Additionally (multi)national approaches prepared by political or technical government advisory bodies and standard setting committees are presented.

For our purposes the terminology suggested by the UN/ISDR (2004) is adequate. Even though this approach has been developed for investigating the impact of natural forces on humans and their socio-economic or environmental context, it can be adapted to the modelling of other kinds of hazards and their effects. In the report risk is defined as "the probability of harmful consequences, or expected losses (deaths, injuries, property, livelihoods, economic activity disrupted or environment damaged) resulting from interactions between natural or human-induced hazards and vulnerable conditions" (UN/ISDR, 2004:3).

yses of natural and man-made hazards, especially terrorism, but no hazard or risk maps are available to the public. Recently occurred catastrophic events are mapped at http://www.eqecat.com/ catWatchREV/index.cfm [17/07/2006]. 
Among natural scientists, engineers, and economists, risk is modelled as the function of an interaction between four basic components: (1) certain hazards, (2) elements exposed to hazardous events with specified characteristics, (3) the susceptibility of the exposed elements to the hazardous impact, and (4) the resulting consequences (see, e.g., Mechler, 2004:16-20; Sinha and Goyal, 2004:107; UN/ISDR, 2004:6). Catastrophe models ${ }^{4}$ have a similar structure (cf. Fig. 1).

In the hazard module extreme natural events such as hurricanes or human-induced events due to terrorism are described regarding cause-effect relationships. In the case of human-induced events data is quite scarce, and the information available might not be representative for other events to come (Kunreuther et al., 2005:218). Additionally, human actions can be directed to produce damages of a certain extent (such as sabotage, terrorism, and war), or they may unintentionally result in damages (like accidents and gradual environmental degradation). For estimating the frequency, severity and locations of future actions of malicious intent, input from experts on threat assessment is needed (Kunreuther et al., 2005:220). The modelling of accidents involves other specific problems: In general, it is very difficult to obtain hazard data, and the data collection process is not standardized, with missing data on small-scale events.

The exposure module contains geographic data on the location of the elements at risk (address, postal code, etc.) as well as information on typical characteristics of the exposed objects and subjects. This includes, e.g., the construction type of buildings, or data regarding the average daytime population and the maximum capacity of schools, shopping centres or stadiums (Balmforth et al., 2005).

The creation of synthetic events is possible via probabilistic models and computer simulation or by the deterministic approach of scenario planning. In conjunction with the hazard module, both approaches are able to differentiate between various qualities of events (is it an industrial accident or vicious sabotage?), related intensities (e.g., in terms of pressure waves of bomb blast) and estimated frequency.

Damage functions are a quantitative estimate of the impact produced by a hazard phenomenon on the elements at risk. Damage functions are region specific and reflect a thorough and detailed understanding of the local conditions and practices (Clark, 2002:185). These are "determined by physical, social, economic, and environmental factors or processes, which increase the susceptibility of a community to the impact of hazards" (UN/ISDR, 2004, vol. II:3), and thus its vulnerability. Location, and its mapping, is an essential compo-

\footnotetext{
${ }^{4}$ FEMA (http://www.fema.gov/plan/prevent/hazus/) offers an open-source multi-hazard catastrophe model (HAZUS-MH MRl); proprietary modelling software and services have been developed by AIR Worldwide (http://www.air-worldwide.com/), EQECAT (http://www.eqecat.com/), and RMS (http://www.rms.com/) [all 17/07/2006].
}

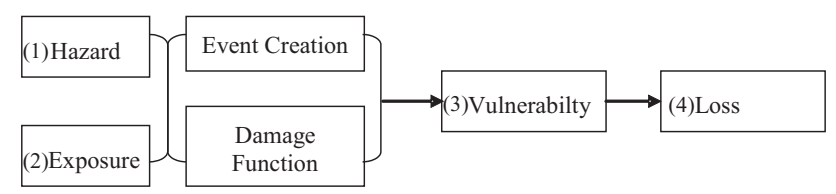

Fig. 1. Structure of risk and catastrophe models (adapted from Grossi et al., 2005:26 ${ }^{1}$ ).

${ }^{1}$ There, components (1)-(4) are represented and "exposure" is called "inventory". We prefer to retain the former term as it is used both in risk concepts and catastrophe models.

nent of vulnerability assessment. It helps to explain what makes people and places where they live, work and play vulnerable to natural, technological, and purposeful threats like terrorism (Abler and Richardson, 2003:123-126).

The definition of risk by UN/ISDR (2004) refers to direct and indirect, economic and human losses including latent (environmental) conditions that may represent future threats. Not all of these can be modelled for mapping. The following section, therefore, introduces a screening approach that explains our selection of human-induced risks based on hazard characteristics, exposure, vulnerability, damage and losses. Instead of the concept of losses, we mainly use a concept of damage which is more general: Losses only contain the economic evaluation of damage of any kind. However, this economic aspect is not covered in this paper. We focus on potential harm to people which is traceable in its immediate, short-term effects. These damages to life and health can, therefore, be categorized as potential direct damages. They are assessed in terms of their physical outcome, without a translation into monetary values.

\subsection{Selecting man-made hazards for detailed analysis}

In its summary account on Germany's hazard potential, BBK $^{5}$ (BVA, 2003:15) states that a special focus is needed regarding major nuclear, chemical and biological accidents, large-scale fires, heavy weather-related events like floodings and storms or earthquakes, and events affecting a very high number of people. These include military conflicts, terrorism, sabotage, organized crime, major accidents and havaries, extreme natural events and epidemics. This account mirrors experiences of past events, assessments of damage potential, and expectations regarding the risk mitigation capacity in Germany.

Not all of the hazards listed above show distinctive spatial features that allow a modelling by the mapping approach

\footnotetext{
${ }^{5}$ To be consistent throughout the article, we use the current names of the institutions involved in civil protection. Since 2004, $\mathrm{BBK}$ is the follow-up institution of the Zentralstelle für Zivilschutz. (Central Institution for Civil Protection) in Germany.
} 
intended here ${ }^{6}$. Potentially ubiquitous and very dynamic hazards such as military conflicts or health risks due to epidemics have to be represented differently for further insights. This also relates to health hazards stemming from the former use of asbestos in construction projects all over Germany, or from fires of the built environment. That kind of hazard is static but scattered over the whole country which makes it hard to point out important localizations of potential damages.

Frequent events resulting in damages that are unlikely to exceed the mitigation capacity of individuals, communities or regional authorities are also not considered. This refers, e.g., to traffic accidents on roads involving human casualties. $^{7}$ It has to be acknowledged, however, that the transportation of hazardous materials can have disastrous consequences and may affect larger areas in Germany. But again it is ubiquitous, not publicly documented and, therefore, difficult to map.

There are other reasons for neglecting minor events when doing research on human-induced hazards: Small incidents in complex systems like industrial plants elude an external observation by non-technical experts. These are hardly documented, and the information regarding small incidents is not published.

To sum up, data availability, coping capacity, cause-effect observations and mapping-related demands serve as exclusion criteria for certain hazards. They also guide the selection process for hazards to be modelled for mapping.

Air traffic accidents have the potential of hurting a large number of people at the same time, thus imposing high demands on rescuing efforts and other risk management measures in case of secondary effects. Industrial facilities as well, namely $N P P$, are potential sources of major hazardous events. Also mass gatherings at sports or arts events, at fairs, shopping centres or large office buildings, etc. may be affected by problems of varied origin. Since a comprehensive assessment of all mass rallies in Germany seems to be an insolvable task, we decided to consider disasters at football games as a pilot example. This also serves as preparatory work for the field of malicious attacks. Another pilot study deals with terrorist attacks on attractive targets like $\mathrm{em}$ bassies.

\subsection{Hazard characteristics of man-made risks}

Both the criteria used for selecting certain man-made risks and aspects of particular relevance for risk mapping serve as a starting point for the typology to be developed. In the fol-

\footnotetext{
${ }^{6}$ For another spatial filtering compare the ESPON 1.3.1-project as described in Schmidt-Thomé (2006:15).

${ }^{7}$ For assessing (and managing) societal vulnerability the frequent events of road traffic accidents, occupational accidents and traditional, everyday crime are normally excluded (Hovden, 2004:631). Societies have developed coping schemes for these risks that are accepted to a certain extent (Starr, 1969).
}

lowing, accidents resulting from technical, human or organisational failures are differentiated from events of deliberate origin.

Accidents displace a normal flow of events. Failures originally happening independently of each other may coincide in their effects, conglomerate, and reinforce or attenuate each other, which makes their analysis quite complex.

Regarding industrial accidents, hazard identification methods based on Failure Modes and Effects Analyses, Hazard and Operations Analysis ${ }^{8}$ may help to provide an extensive overview of what can go wrong and how likely this might be, but as long as human actions are integrated with technology surprises are possible. For achieving a comprehensive modelling of accidental man-made hazards, it is, therefore, necessary to complement the understanding of processes by other means (cf. Sect. 4).

This is also essential for the assessment of malicious actions. As an outcome of continuously evolving motivations to attack they cannot be fully explained by either observable events or analyses of structural vulnerabilities. Malicious actions arise out of deliberate preparations of people who are informed about the history of past attacks while taking into account possible countermeasures to fend them off. This generates a dynamic uncertainty in time regarding all deliberate malicious actions, and an interdependent vulnerability between potential targets of terrorism. The targets who prepare for threats are less likely to be attacked because of heightened costs for the aggressors (Michel-Kerjan, 2003). Consequently, this raises the probability of attacks on other targets. But as long as potential targets are interrelated (e.g., by business connections or physical links like supply-chains) the threat remains high even for the partners that do not have to experience any direct attacks (Kunreuther and Heal, 2003).

Regarding the mapping of risk, it is important to distinguish the location and spatial dimensions of perils as well as the number of possible sources of unwanted events. Aspects with this particular relevance are highlighted by the grey background colour in Table 1 .

There are fixed locations as for accidents at industrial plants or variable ones as in the case of air traffic accidents that can literally occur anywhere. The boundaries with respect to spatial dimensions may be marked by the location of a hazard itself (accident in a football arena), but others like hazardous releases from chemical plants may spread past the zoning of the source. The number of possible locations of a certain type of hazard ranges from only a few as in the case of nuclear power plants in Germany to an unmanageably high number of, e.g., chemical, facilities using or producing hazardous materials.

Concerning temporal aspects of hazards, the time of occurrence can either be restricted - for example to the schedule of mass rally events - or be variable as for accidents at industrial

\footnotetext{
${ }^{8} \mathrm{~A}$ short overview of various approaches in quantitative risk analyses is presented by Kaplan et al. (2001).
} 
Table 1. Hazard characteristics of man-made risks (grey background and bold fonts imply aspects of particular relevance for risk mapping and criteria used for selecting certain man-made risks, respectively).

\begin{tabular}{llll}
\hline Domain & Attribute & Characteristic values & \\
\hline Hazard & kind & malicious, accidental & \\
& intensity & strong (disastrous) & weak \\
& location & variable (anywhere) & fixed \\
& number of locations & many places & few places \\
spatial dimension & wide-ranging, spreading & punctual \\
& time & variable (anytime) & fixed / at limited \\
& & times & short-term \\
& duration & long-lasting (e.g., & permanent emissions) \\
& frequency / probability & frequent / high & rare / unlikely \\
& probability & moderate \\
\hline
\end{tabular}

plants that may happen any time. The duration of a hazard may range from short-term (for most of man-made risks) to long-lasting as in continuous emission of small amounts of radiation to the environment by a nuclear power plant.

A fact of great influence on risk assessment is the frequency of a hazard ranging from very rare to rather frequent events with low to high probability, respectively. Whereas a maximum credible nuclear accident can be considered unlikely on German territory, cases of fire are happening quite frequently, therefore displaying a high probability. At the same time, they can be managed to a large extent with the existing resources provided.

One aspect that marks a clear distinction between accidental risks and risks of malicious nature is the dynamics of hazards. Most man-made perils change moderately over time as a result of technological and other developments - the use of larger aircrafts and the global increase of travellers result in a shift of the hazard in the domain of air traffic accidents. Terrorism, however, can alter almost immediately, e.g., by changes in the doctrines of the assaulters regarding the usage of weapons of mass destruction. The dynamics of terrorism risk is, therefore, immensely high.

As explained before (and highlighted in Table 1 in bold), we have chosen to concentrate our efforts on hazards of disastrous intensity. Realizations thereof are rare, and especially the short-term consequences ask for coordinated preparations to manage the risk. Our contribution consists in the mapping of the selected hazards.

2.4 Exposure, vulnerability and damages in the domain of man-made risks

Special characteristics of human-induced risks are not restricted to the hazard domain; they also extend to aspects of exposure, vulnerability and damages. These are listed in Table 2 and, once again, aspects with a special relevance for mapping are highlighted in grey.

Regarding exposure, a basic distinction is given by the different kinds of elements at risk which comprehend humans, the environment, physical assets like buildings, production processes and cultural values. Traffic accidents and mass rally events tend to primarily generate human casualties whereas industrial accidents have the potential to additionally harm assets, production processes and the environment. In the case of terrorism, cultural values form an important part of exposure. As the undermining of society by the means of attacking its fundamental values forms one part of the bundle of aims of the assaulters (OECD, 2003:104; Laqueur, 2003), they accordingly choose their targets.

Due to differences in spatial dimensions, the granularity of risk-prone areas varies. At least two cases can be distinguished:

- man-made risks with the potential of affecting extended geographical areas, like accidents in NPP,

- events happening on a limited local dimension, especially when a major part of the elements at risk is represented by the hazardous object or system itself, for example the venues of mass gatherings like football stadiums.

In the first case, it is efficient and thus reasonable to use general exposure data like the stock of residential buildings or population density as compiled by Kleist et al. (2006) or INFAS Geodaten (2001), respectively. General exposure data is commonly available at the level of communities as the finest resolution. This, however, is too aggregate for smallscale events. Regarding elements affected at a local level, 
Table 2. Characteristics of exposure, vulnerability and damages regarding man-made risks (grey background and bold fonts imply aspects of particular relevance for risk mapping and criteria used for selecting certain man-made risks, respectively).

\begin{tabular}{|c|c|c|c|}
\hline Domain & Attribute & \multicolumn{2}{|l|}{ Characteristic values } \\
\hline \multirow[t]{2}{*}{ Exposure } & elements at risk & \multicolumn{2}{|c|}{$\begin{array}{l}\text { human, environment, physical assets, production } \\
\text { processes, cultural values }\end{array}$} \\
\hline & granularity & general & local \\
\hline \multirow[t]{2}{*}{ Vulnerability } & $\begin{array}{l}\text { degree of structural } \\
\text { vulnerability of elements } \\
\text { at risk with respect to } \\
\text { each hazard }\end{array}$ & $\begin{array}{l}\text { very vulnerable to all } \\
\text { kinds of hazards }\end{array}$ & $\begin{array}{l}\text { no structural } \\
\text { vulnerability to many } \\
\text { hazards }\end{array}$ \\
\hline & $\begin{array}{l}\text { distance of object / } \\
\text { person to origin of hazard }\end{array}$ & close & remote \\
\hline \multirow[t]{3}{*}{ Damages } & kind & \multicolumn{2}{|c|}{$\begin{array}{l}\text { direct/indirect: physical, psychological, } \\
\text { economical, political, societal }\end{array}$} \\
\hline & $\begin{array}{l}\text { temporal aspects of } \\
\text { occurrence }\end{array}$ & delayed, long-lasting & $\begin{array}{l}\text { immediate, short- } \\
\text { term }\end{array}$ \\
\hline & traceability & non-traceable & $\begin{array}{l}\text { traceable (clear } \\
\text { cause-effect- } \\
\text { relationship) }\end{array}$ \\
\hline
\end{tabular}

this information is not sufficiently precise; the same holds true when a detailed analysis of possible local effects of a large-scale event is intended. Hence, it is necessary to complement general aggregate data with a regional stock of exposure, which means that an additional case-specific inventory of individual elements at risk has to be built up. Thieken et al. (2006) provides such a mapping approach to disaggregate exposure data for all the communities in Germany.

For several reasons, vulnerability marks the most difficult topic within the context of mapping human-induced risks: First of all, its degree is distance-related - it is generally increasing with a declining physical distance to the possible locale of an accident or malicious attack. An object close to a road but far away from railway lines would thus be more vulnerable to car accidents than to railway accidents. Some hazards like air traffic, however, are not locally bound inasmuch as they cover extended geographic areas. Additionally, risk can be altered by the exposed elements themselves. For example, the vulnerability of football fans to a harmful event taking place in a stadium undoubtedly depends on their decision of becoming a participating spectator of a certain match or not.

Even though the points mentioned above also apply to natural hazards, they pose a special problem for the mapping of man-made risks. This is related to the very heterogeneous hazard characteristics. In theory, vulnerability has to be defined with respect to each specific form of hazard, which we will name "structural vulnerability". 9 Protection measures

\footnotetext{
${ }^{9}$ The intrinsic vulnerability of a person or an object that is related to the condition of being young or old, strong or weak,
}

that may, e.g., prevent the intrusion of fire into a house might be ineffective against toxic substances, therefore leaving the house vulnerable to the latter peril.

But considerations that detailed are hardly feasible within the scope of risk assessment intended here, i.e. covering the whole of Germany: The necessary inventory of exposure would not only have to include the geographical location of all elements at risk, one by one, but also information on its characteristics with respect to structural vulnerability of all man-made risks considered. Therefore, the development of a methodology to assess the risks has do be done for specific types of hazards ${ }^{10}$, and starting at selected areas of limited dimensions that will be gradually expanded.

Another reason for being selective is that it is very hard to get statistical data or detailed case studies on the elements at risk actually affected by a human-induced disaster. Direct losses might be documented, but reports hardly reveal aspects like the distance to the locale of an event or criteria with respect to structural vulnerability. Especially data on elements sensitive to terrorist actions such as critical infrastructure is confidential (Kunreuther et al., 2005:220). Data gaps, therefore, have to be filled: The vulnerability stem-

retrofitted or not, is part of the structural vulnerability and determines the amount, kind and quality of risk mitigation necessary.

${ }^{10}$ The typology presented here is intended to facilitate risk mapping. It is developed from a hazard point of view. Other approaches - like the one used in the ESPON 1.3.1.-report (Schmidt-Thomé, 2006) - are based on the risk perspective concept as suggested by the WBGU (2000). That concept allows highlighting specific interrelations between hazards, risk perception and societal response. For an application to systemic risks cf. Klinke and Renn (2006). 
ming from a hazard is estimated by designing appropriate proxy parameters from the available data. Coarse estimates during the early stages of our research, in conjunction with greater uncertainties, can be improved along with the knowledge developed over time.

Another view on the risks is provided by dealing with the realisation thereof, i.e. the respective outcome of disasters. Damages may be categorized depending on their kind or on temporal aspects of occurrence and traceability. For all disastrous accidents and malicious actions that might happen in Germany, the damages can consist to an important extent of human casualties surpassing those with respect to physical assets. Although psychological consequences and socioeconomic damages form an important part of the outcome of disasters, especially in the case of accidents in nuclear power plants and also terrorism, they are beyond the focus of the "Risk Map Germany" (RM) research framework. This is also the case regarding delayed effects with respect to human health that may be connected to immissions of toxic agents resulting from accidents in chemical facilities or NPP. The limited traceability of adverse effects to particular events, combined with difficulties to record potential causes and effects and to evaluate them statistically, forces us to exclude this aspect of human-induced risks from mapping. Only the direct damages/casualties to the people living around the hazardous object are considered.

Many man-made hazards like traffic accidents or mass rally events primarily produce direct kinds of damages such as vehicle or cargo destruction and human casualties. Especially industrial risks like NPP and chemical facilities have the potential to trigger major additional indirect damages due to the interruption of their business and the one of business partners or of normal life in the affected area. Aside from the economic damages due to activity reduction and follow-up effects (unemployment, emigration, living expense surges, real estate depreciation), further consequences occur when critical functions are hit that have to be re-established as quickly as possible.

Terrorism is special in so far as its consequences are directly linked to the form of attack chosen by the assaulters and, therefore, hard to predict. However, it can be assumed that a huge proportion of indirect damages might be a prior intention by certain assaulters. These happen when important structural elements like traffic nodes (e.g., railway stations) are hit. Another form of indirect damage of terrorist acts (including sheer threatening) is marked by psychological consequences. However, for maintaining the comparability with research on natural catastrophes within RM we only consider direct damages. For accidental risks, they are assessed as potential human casualties, and for terrorist threats they enter as an important factor determining the attractiveness of certain targets.

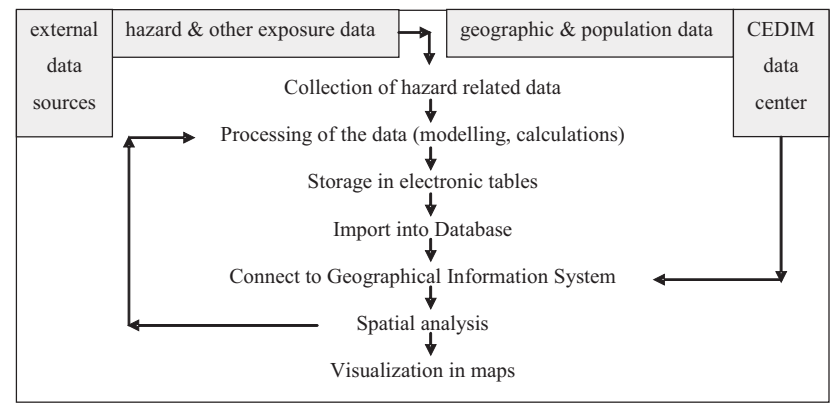

Fig. 2. Flowchart for the visualisation of information.

\section{Processing and visualization of information}

The presented typology of risks clearly shows that humaninduced risks are very heterogeneous. As a consequence, it is hard to find spanning scientific concepts and studies as well as detailed overall event data for this field of research. Haimes (1998) gives a comprehensive summary of work in risk assessment in general.

In order to implement the risk analysis concept through mapping, Geographic Information Systems (GIS) and database systems are widely used. Our data collected from diverse sources is processed for modelling and calculation purposes. If necessary, extraterritorial experiences serve as a backup for the collection of corresponding German data at the micro-, meso- and macro level. Data collection, processing and visualization procedures are illustrated in Fig. 2.

Hazard and exposure related statistical data are collected from both primary and secondary sources including the internet and concerned organisations such as authorities or companies. The data of potentially hazardous objects or exposed elements (stadiums, NPP, etc.) include real world geographic coordinates, addresses, and hazard specific information which are stored in tables (Microsoft Excel). Afterwards, they are imported into a database management system software (MySQL) for further analysis and data base operations before being included into the GIS software (ESRI ${ }^{11}$ ArcGIS) for spatial analyses.

Different geo-data such as administrative boundaries, road network, rivers, digital elevation models as well as population data at different resolutions within the spatial framework of Germany are gathered internally from the CEDIM data center and handled with ArcGIS software.

ArcGIS provides various facilities for the spatial analysis and visualization of data: The buffer function, e.g., allows to create buffer polygons to a specified distance around an input feature. We use this in order to model air traffic risk by designing buffers around airports (cf. Sect. 4.2). The overlay

\footnotetext{
${ }^{11}$ Environmental Systems Research Institute (ESRI), one of the world's leading GIS software companies, developed ArcGIS: An integrated collection of GIS software products (http://www.esri.com [17/07/2006]).
} 
Table 3. Factors influencing the hazard of radioactive releases from German NPP at facility level.

\begin{tabular}{|c|c|c|}
\hline Influencing factor & Mode of influence & $\begin{array}{l}\text { Characteristic values in } \\
\text { Germany } 1\end{array}$ \\
\hline Power $^{2}$ & $\begin{array}{l}\text { The maximum quantity of radioactivity to be released from a } \\
\text { NPP depends on its inventory. More power means a bigger } \\
\text { inventory (not proportional, though, as both technology and } \\
\text { efficiency of the plant must be taken into account). }\end{array}$ & $\begin{array}{l}\text { The NPP have an electri- } \\
\text { cal power of } 806 \mathrm{MW} \text { up to } \\
1400 \mathrm{MW} \text {. }\end{array}$ \\
\hline Reactor type ${ }^{3}$ & $\begin{array}{l}\text { In Germany two different types exist: Pressurized water reac- } \\
\text { tors (PWR) and boiling water reactors (BWR). PWR are in- } \\
\text { trinsically safer because they have two separate cooling water } \\
\text { circulations, the steam in the reactor is from a separate source } \\
\text { and the special construction cares for a falling pressure with } \\
\text { a rising temperature. }\end{array}$ & $11 \mathrm{PWR}, 6 \mathrm{BWR}$ \\
\hline $\mathrm{Age}^{4}$ & $\begin{array}{l}\text { Aging in NPP causes different problems: } \\
\text { - Technical: Mechanical components, buildings and built in- } \\
\text { frastructure, electronic and information technologies } \\
\text { - Operation systems } \\
\text { - Documentation } \\
\text { - Maintaining quality of staff (loss of employees, difficulties } \\
\text { in finding well-educated personnel) }\end{array}$ & $\begin{array}{l}\text { In } 2005 \text { the NPP had an } \\
\text { average age of } 23.4 \text { years, } \\
\text { with the oldest one being } \\
\text { built in } 1974 \text {, the most re- } \\
\text { cent one in } 1989 \text {. }\end{array}$ \\
\hline
\end{tabular}

${ }^{1}$ Cf. Bundesamt für Strahlenschutz (BfS, Federal Office for Radiation Protection) - Kernkraftwerke in der Bundesrepublik Deutschland (Nuclear Power Plants in Germany), http://www.bfs.de/kerntechnik/ereignisse/standorte/karte_kw.html [17/03/2006].

2 Own consideration and comparison with the exposure rates of NPP in normal operation as published by Koelzer (2005).

3 Technical details can be found at http://www.wien.gv.at/wua/atom/glossar/s.htm and http://leifi.physik.uni-muenchen.de/web_ph10/ umwelt-technik/13kkw/index.htm [both 17/03/2006].

${ }^{4}$ Cf. considerations of RSK (2004).

function combines different layers and creates a new layer with combined attributes. For example, after having created a buffer zone around NPP, it can be overlaid with a population density layer to extract further attributes (cf. Sect. 4.1).

Thus, the spatial analysis functionality of GIS can reveal new aspects, and thereby help to analyse and understand the effects of any disaster. This may improve the risk modelling process. In addition, the GIS facilitates the illustration of hazard, exposure, and risk by various maps that can be created within the computer system.

\section{The implementation of the risk assessment concept: mapping man-made risks}

\subsection{Nuclear power plants}

At present, 17 NPP with a total power of $21 \mathrm{GW}$ are operating in Germany. The German government has decided to decommission all German NPP within the next twenty years ${ }^{12}$ due to the aging of the facilities, extensive public discussion

\footnotetext{
${ }^{12}$ Deutscher Bundestag: Gesetz, zur geordneten Beendigung der Kernenergienutzung zur gewerblichen Erzeugung von Elektrizität. (German Parliament: Law concerning the orderly termination of nuclear energy usage for commercial production of electricity)
}

on the safety of these plants and problems with safe storage of atomic wastes. As long as these governmental plans are not fully carried through, it is worthwhile to consider this wide-ranging hazard. We focus on short-term effects of possible, although low-probability, releases of radioactive substances during continuous operation.

4.1.1 State of the art and results of previous risk assessments

The hazardousness of NPP originates from potential releases of radioactive substances. It is affected by the amount of radioactive materials contained in the facilities and by their technical standards regarding substance release prevention. Institutions like the Gesellschaft für Anlagen- und Reaktorsicherheit (GRS, Society for Facility and Reactor Safety) a German organization responsible for supervising technical aspects of nuclear power plants - have been publishing detailed studies about safety issues in such facilities (cf. GRS, 2005). Based on these studies we derive some primary factors influencing the hazard of radioactive releases in German NPP. They are shown in Table 3.

Since 2002, the GRS has begun a probabilistic safety analysis (PSA), a far-reaching concept for the assessment of the 
technical safety for all German NPP ${ }^{13}$. PSA is meant to estimate the likelihood of an accident with damage to the core of the reactor or one that cannot be enshrined by the internal safety barriers of the plant, respectively. The estimates are made by looking at both the technical components of the reactor and the safety barriers for each scenario defined. A methodology including large event trees and several computer models is used to analyse possible events of importance. Although the methodology by itself is probabilistic, the results are not: Only few likelihood values for certain deterministic events are given without distinguishing between different release intensities. This does not allow any further probabilistic analysis of the release hazard. The probability for core melt phenomena (core damage frequency, CDF, as one kind of events considered) of all intensities of a German NPP lies between 2.0E-07 and 5.3E-06 per year. Figure 3 gives some examples of CDF values for German plants.

PSA allows figuring out and improving the problems which the technical safety concept might include (cf. Berg, 2004). But PSA does not yet contain information on other factors relevant to the hazard of radioactive releases. For example, the source term (or its probability function, respectively) is determined by constructional characteristics of the reactor like its type and electrical power produced. These are incorporated into PSA whereas the factor "type of incident" is only partly worked in. The aging of NPP (cf. Smith et al., 2001) $)^{14}$ as well as human mistakes and errors in connexion with the general safety management in plants are also not covered. As a consequence, there is, e.g., continuous effort to systematically incorporate aging phenomena into the determination of PSA values. In Europe, a research "Network on Incorporating Ageing Effects into Probabilistic Safety Assessment (APSA)" funded by EU has started to address this task since $2004 .{ }^{15}$ Regarding the safety management or safety culture in the operating company, Müller et al. (1998) and Sorenson (2002) conclude that human aspects should be considered an integral part of safety systems. They show up in organizational performance and individual striving for safety in the work area. Employees leaving the NPP take away a lot of valuable knowledge. Therefore, it is necessary to train the staff continuously and to educate new personnel. The last part of this claim is a problem for German plants because of the intended shutdowns of NPP which makes these jobs less attractive. According to our own findings, ${ }^{16} 19.9 \%$

\footnotetext{
${ }^{13}$ For an overview on foundations and methods of PSA as a standardized successor of former probabilistic approaches called Probabilistic Risk Analysis, cf. Bedford and Cooke (2001).

${ }^{14}$ One problem with respect to aging of the plants is that they contain steel reactors that wear out. The microscopic splitting of a steel reactor can only be measured by complicated analyses.

15 APSA website: http://www.energyrisks.jrc.nl/APSA/ [19/03/2006].

${ }^{16}$ Calculations based on http://www.bfs.de/kerntechnik/ ereignisse/berichte [19/03/2006].
}

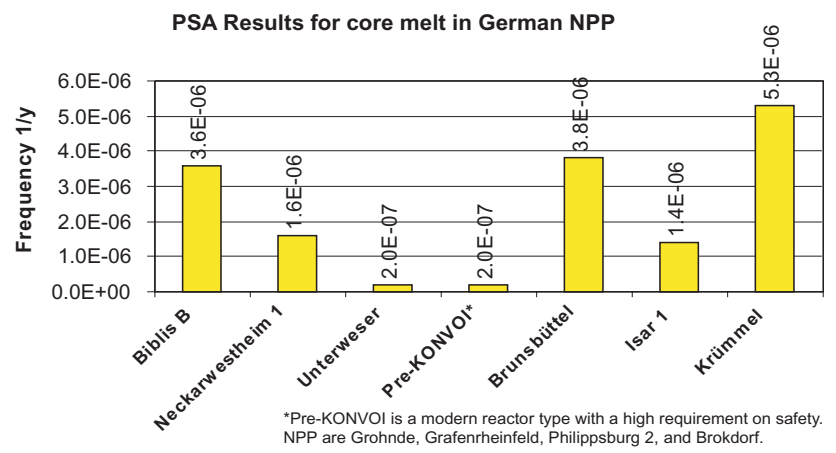

Fig. 3. PSA results for German NPP. Data source: Bundesamt für Strahlenschutz (BfS, Federal Office for Radiation Protection).

of unwanted events (reportable events, cf. Sect. 4.1.3) in German NPP during the period of 1994-2004 were caused by human errors and mistakes.

Despite their omissions and limitations, concepts like PSA have been forming the basis of advanced technical studies regarding the risk of NPP. Some studies - for example, US NRC (1990) - are very complex and require lots of technical knowledge as well as an extensive amount of data. Considering the fact that this data is not always available in the quality needed for detailed analysis, other studies like SchmidtThomé (2006) use simplified concepts and indicators.

The ESPON-project as outlined in Schmidt-Thomé (2006) is a study covering risks of different hazards. It uses a very simple hazard indicator with respect to NPP, namely the existence of a plant in operation. Based on the experiences of the Chernobyl accident, it is assumed that a NPP imposes a very high hazard for its immediate neighbourhood within a radius of $30 \mathrm{~km}$, a medium hazard for the surrounding area of up to $300 \mathrm{~km}$ and no hazard for greater distances. Vulnerability is not modelled case-specifically with respect to different hazards in this study.

The study of Kromp et al. (1999) is a recent example for detailed hazard research based on quantitative safety analysis values like PSA. It was done on behalf of the Expert Authority of the Österreichisches Umweltbundesamt (Austrian Federal Office for Environmental Protection and Control). The authors investigate the probability of radiological exposure stemming from all European NPP. With respect to the likelihood of release events, the study uses values generated probabilistically similar to PSA ${ }^{17}$. The source term of all substances and their amounts released, thereby determining the local intensity of a radioactive hazard, is given by employing one typical scenario. The subsequent deposition of nuclear substances to the ground is calculated by using a simulation of certain meteorological conditions determining the

\footnotetext{
${ }^{17}$ One part of the study uses Large Release Frequencies for each reactor type, which are derived from CDF values. In another part, calculations are based on a value given by the International Atomic Energy Agency as a guidance level for any reactor type.
} 
Reportable events $($ INES $=1$, Category $=E)$

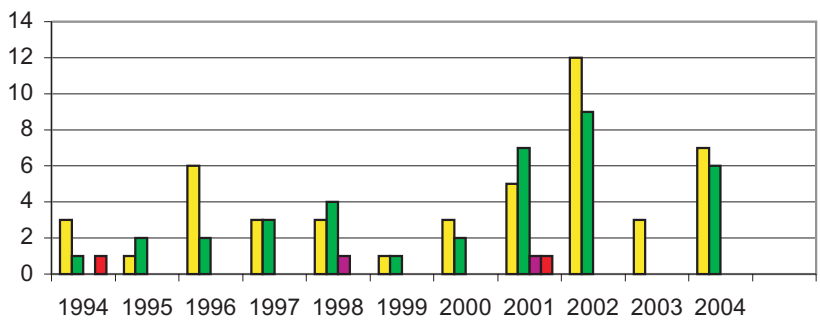

$\square$ INES 1 पCategory E $\square$ INES 2 Category S

Fig. 4. Number of reportable events of German NPP between 1994 and 2004 (Data: BfS).

spreading of radioactive agents. As a result, the researchers created a map showing the geographical distribution of the probability of being exposed to radioactivity, and tables indicating the radiological exposure of various countries. Unfortunately, the study is almost completely limited to the hazard part of the risk and - with the only exception of a value of soil contamination - neglects the elements at risk exposed to it (like humans and property), and their vulnerability.

Since there is usually no direct damage to property due to radioactivity releases except to the plant area itself we focus on humans with respect to exposure and vulnerability. Complex connexions in the absorption of radiation doses by the human body may generate a broad array of medical conditions. At least two assessment strategies regarding health risks can be discerned in the literature: A very detailed approach is used, e.g., by BMU (2001) or US NRC (1990), and a simplified approach is used by Weil (2003).

Weil (2003), head of the core safety department of the BfS, assesses the monetary value of health risks and property damage for the hazard scenario of a major accident at the German NPP located in Biblis. The health risk considered is defined as the danger of getting cancer, which leads to costs for treatment or lethal consequences. For determining health risks Weil (2003) does neither differentiate between ways of incorporation of radioactivity nor between certain groups of the population as stemming from gender and age, but just gives an average percentage of people affected. This ratio is multiplied with the number of the local population. Together with assumptions on treatment costs and costs of lethality as given by Ottinger et al. (1990) and Hohmeyer (1989), the sum of health costs is obtained and added to the costs due to property damages.

BMU (2001), in contrast, demonstrate clearly that calculating health effects and health costs from radiological activity rates can be an extremely complex task. They distinguish between different medical mechanisms caused by different forms of incorporation of radioactivity to the human body via external radiation, breathing and ingestion - while considering that these effects are also influenced by dose mitiga- tion measures of emergency response actions.

Another study, US NRC (1990:3-17), which includes both hazard and vulnerability assessment, distinguishes four types of indicators for determining the vulnerability of humans towards radioactive releases, i.e. early fatality risk, latent cancer fatality risk, population dose within 50 miles of the site and population dose within the entire site region. The values, however, are calculated only for certain US-plants and they are based on assumptions covering both the local technical plant features as well as their environment. Consequently, the assessment cannot be directly transferred to the German context. Furthermore, the calculations are, again, quite complex and go beyond the scope of this study.

\subsubsection{Data for assessing the risk of NPP}

Existing PSA values for German NPP can serve as a basis for hazard assessment. Since this primary indicator has some shortcomings, we have looked for data in support of other approaches suitable to flank PSA values. Besides that, Greenpeace states a critical view of relying solely on this mainstream indicator and shows contradictory study results with respect to the assessment of nuclear risk (cf. Greenpeace, 1998).

Since 1975 , BfS has constantly supervised the nuclear facilities and regularly informed the public about all German NPP both on basic technical data like reactor types, inventory, starting time of operation and age, respectively, as well as on their findings regarding the safety of the plants. Backing their work, by the act of law a reporting system was installed to document safety problems, enabling the BfS to publish descriptive findings from statistical evaluations on reported incidents.

In the case of an unwanted event taking place in a facility, the operating company (operator) is obliged to report to the BfS (reportable events). The operator documents, categorizes and publishes these events in order to improve the safety status in the plants. The German scaling system for these reportable events is categorized into 4 levels: S, Sofortmeldung (immediate notification); E, Eilmeldung (urgent notification, report within $24 \mathrm{~h}$ after the event); N, Normalmeldung (normal notification, 5 days) and V, Vor Beladung des Reaktors (before charging the reactor, 10 days). The internationally applied INES (International Nuclear Events Scale) system differs from the German scaling as it is using a numerical system: No significance (category 0 ), termed incidents (13 ), and termed accidents (4-7).

Between 1994 and 2004, according to BfS, German NPP reported 2300 events but none was categorised higher than INES 2, as illustrated in Fig. 4.

We use this data on reportable events along with information about the age of NPP for constructing our hazard assessment model. For mapping vulnerability, we rely on information available within the CEDIM framework: This data consists of areas of homogeneous mean population densi- 
ties $^{18}$ within the communities as calculated by Thieken et al. (2006). Their study is based on information on residential population provided by INFAS Geodaten (2001) as well as on land use information developed by the European project CORINE land cover (CLC).

4.1.3 Methods for assessing and mapping the nuclear risk in Germany

Despite the limitations already discussed in Sect. 4.1.1, some results of former studies on nuclear risk are fundamental to the development of our methodology for assessing and mapping the risk of NPP in Germany.

In our studies done on NPP aging ${ }^{19}$ the following contingency between the frequency of reportable events of INES 1 and 2 and the facilities' age can be observed.

Figure 5 shows the number of reports in German reactors which are categorized into age-classes for a better overview. In Germany, 17 NPP are in operation, none is older than 32 years and none is younger than 14 years ${ }^{20}$. The reports of all NPP counted over a period of the last 11 years are used. They are categorized as INES 1 or 2 without exception. The difference in severity of these categories is taken into account by a weighting factor two for INES 2 events which means that these events are counted twice. Although the set of NPP is small, Fig. 5 clearly shows that the older reactors have more reportable events. This is in line with research conducted on aging of NPP in different parts of the world: With respect to the risk of core damages, studies mention "from 10 to more than $1000 \%$ [of] increasing by year in operation" (Vesely et al., 1990 as cited in IRSN, 2005:16) for CDF. For our hazard assessment we, therefore, include a correction factor based on empirical findings reflecting the age of the facilities.

The hazard per se is of international dimensions, especially due to the influence of meteorological conditions such as direction and speed of wind, stability of atmospheric layers, humidity, and rainfall. Together they form a very complex interplay of factors impinging on the dispersion of the nuclear agent. Kromp et al. (1999) argue conclusively that up to 89 percent of the probability of radiological exposure in Germany stem from foreign countries. Unfortunately, this has to be considered a rough estimate, as the data on NPP in foreign countries, if available at all, are not directly comparable to the data on German reactors, thus imposing great uncertainties with respect to this hazard. As there is hardly any justification to model the dispersion of radioactivity for

\footnotetext{
${ }^{18} \mathrm{~A}$ homogeneous mean population density is assumed in areas with the same land use. The mean values are corrected per community.

${ }^{19}$ While most international studies on this topic like Smith et al. (2001) are cause-based, i.e. an aging reliability-physics model is applied to the existing PSA risk model, our approach, on the contrary, is effect-based.

${ }^{20}$ In 2004, source: http://www.bfs.de/kerntechnik/ereignisse/ standorte/karte_kw.html [19/03/2006].
}

Reportable events per NPP in operation

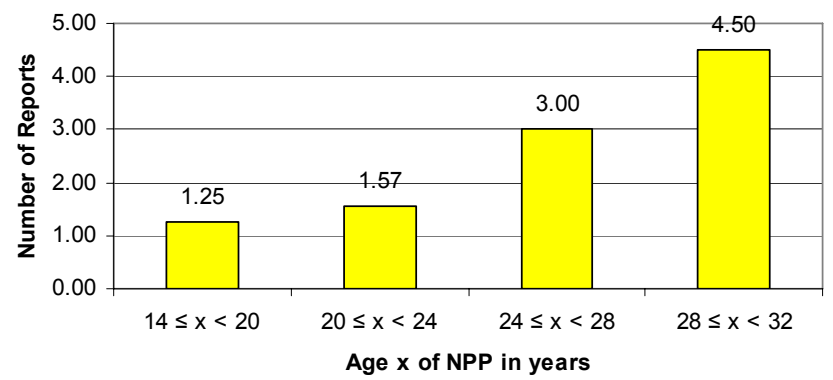

Fig. 5. Reports per NPP in operation.

Germany without detailed information from abroad, we confine ourselves to the local areas, which would be undoubtedly and severely affected by a radioactive release. In BMU (2001), a buffer zone with a radius of $30 \mathrm{~km}$ around a plant is proposed for immediate action regarding protection measures. $^{21}$ We introduce the same buffer zone in our modelling and mapping approach.

To sum up our considerations on the choice of an appropriate model, we decided to use a simple hazard model based on information available for Germany, i.e. PSA values and age data combined with empirical findings on the number of incidents, resulting in the following index:

Hazard index $h=f$ (PSA, age factor)

In detail, we use an age factor reflecting the relative increase in reportable events for NPP of different age classes compared to the youngest cluster. These factors ranging from 1 for the most recently built class of reactors to $3.6^{22}$ for the oldest NPP are multiplied with the PSA value for each plant. The resulting values are then normalised, i.e. the highest value is given the index value 1 while the other values are adjusted accordingly. ${ }^{23}$ Consequently, the "safest" plant is assigned an index value of only 0.0146 in comparison with 1.00 for the most hazard prone one.

As we do not model dispersion effects, we cannot calculate detailed health risk and consequently only include the predecessor of such calculations in our vulnerability model, namely values of population densities. This results in the following index:

Vulnerability index $v=f$ (population density within

a radius of $30 \mathrm{~km}$ around NPP)

\footnotetext{
${ }^{21}$ This is the same radius as chosen for evacuation following the Chernobyl accident.

${ }^{22}$ The NPP pertaining to the oldest age-class had to report on average 3.6 times as many events as the most recently built NPP, i.e. 4.5 reports/ 1.25 reports.

${ }^{23}$ The respective product of PSA and age factor is divided by the highest value calculated.
} 


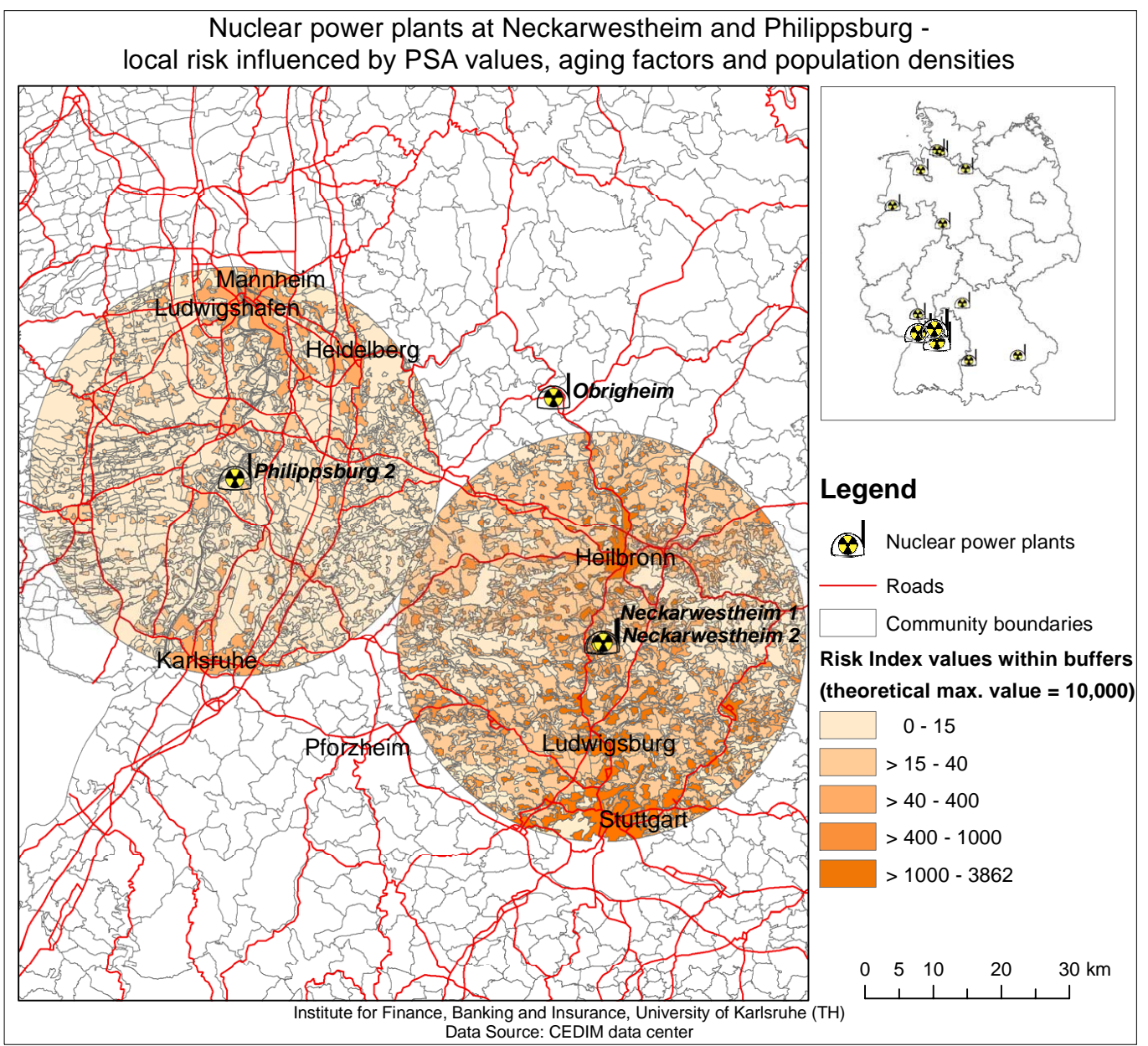

Fig. 6. Local risk map around the nuclear power plants Neckarwestheim 1, Neckarwestheim 2 and Philippsburg 2.

Population density values in Germany vary between 0 and 14419 inhabitants per $\mathrm{km}^{2}$ for areas of homogeneous mean population density within a community as given by Thieken et al. (2006). This data is again normalised for mapping purposes to obtain values between 0 and $1 .^{24}$

For calculating the final risk index $r$ within the buffer zones, we multiply the hazard index values $h$ and the vulnerability index values $v$. Due to the normalisation effected in the former steps, this results in very low values of magnitudes smaller than one. That is why this product is multiplied by 10000 for displaying purposes, leading to the formula:

Risk index $r=h * v * 10000$

\footnotetext{
${ }^{24}$ As mentioned before, these values only reflect the residential population, which means at night-time. People moving in or out of certain areas during day-time - for work, school, shopping, etc. are not registered. For a more detailed approach see Balmforth et al. (2005).
}

\subsubsection{Results of the risk assessment}

Looking at the spatial distribution of NPP reveals that most of them are located at the northernmost and southernmost parts of Germany with some agglomeration at a very close distance to each other. Figure 6 - as an example of the results of this risk assessment process - shows the environment of three German reactors at Neckarwestheim and Philippsburg including both hazard and vulnerability information. Within a radius of $50 \mathrm{~km}$ of these plants one further reactor (Philippsburg 1) cannot be taken into account due to missing PSA values (although PSA values exist for all 17 NPP, they have been published only for 10 NPP so far), a second one (Obrigheim) was decommissioned in May 2005.

It is evident that some cities ${ }^{25}$ are located within the buffer zones of $30 \mathrm{~km}$ around the NPP. Their population is endangered, therefore, by nuclear accidents. In the exemplary case

\footnotetext{
${ }^{25}$ These are Karlsruhe, Mannheim, Ludwigshafen and Heidelberg in the case of NPP Philippsburg and Stuttgart in the case of NPP Neckarwestheim.
} 
mapped in Fig. 6, the values of the risk index $r$ vary between below 1 (very low risk) for nearly one fourth of the cases and above 1000 (high risk) for the top 3.6 percent, the majority of the values (64\%) being at a low to medium level of risk between 1 and 100. Although many densely populated cities are located near the Philippsburg plant, the highest index value within these cities is 139 (for parts of Heidelberg), at a medium level of risk. This is due to the low hazard index value $h$ for NPP Philippsburg (0.018) which is nearly 24 times lower than the sum of those for the Neckarwestheim plants $(0.421+0.015=0.436)$. Consequently, areas with considerably higher values of risk (above 3000) are located in Stuttgart, Ludwigsburg, Heilbronn, and Fellbach where both hazard and vulnerability values are elevated. The risk index values for the area located in the intersection of the buffer zones around the NPP are still low because of the very low population density there.

\subsubsection{Discussion of the NPP risk assessment approach}

The methodology and parameters chosen for building our risk index are subject to discussion. Within a multi-hazard study of limited scope, the degree of detail in the assessment of hazard, vulnerability and risk has to be chosen carefully.

For the hazard assessment regarding plant safety, it seems reasonable to draw upon the scientifically accepted concept of PSA supplying individual values for each reactor. Other approaches use no distinction between different plants as in Schmidt-Thomé (2006) or only values for certain reference NPP and minimum safety goal values, respectively (Kromp at al., 1999). Adding correction factors based on statistical findings can help to overcome the problem of passing over aging effects by PSA. Nevertheless, the use of PSA for German NPP is limited due to the nondisclosure of the results for some plants thus restricting the implementation of the methodology for whole Germany as for now. Further research should incorporate all existing values.

Regarding the vulnerability assessment, we use population density information at the highest resolution available for differentiation with respect to this parameter. Since a more detailed assessment of the vulnerability of people by in-depth medical considerations cannot be part of this study, it is left to further research. One step that should also be included in future research is a consideration regarding the whereabouts of people during day-time. Other very important aspects within the risk of NPP are indirect economic effects, which are to be subsumed under vulnerability assessment, too. However, within the first stage of the framework of the overall CEDIM project they are not included in the considerations.

As a conclusion, the risk index is a simple approach for assessing the risk due to NPP. It is specifically adopted to the characteristics of this very complex form of risk and, therefore, hardly comparable to our assessment of other forms of man-made perils.

\subsection{Air traffic}

In Germany, there are 17 international airports (as of 2004) and some regional airports handling in total about 2.7 million Instrument Flight Rules (IFR) flights ${ }^{26}$ per year as well as even more small airports exclusively used for air sports purposes. Deutsche Flugsicherung (DFS, German Organisation for Flight Security) controls and guides the non-sport flights from start till landing. The number of flights as well as of passengers and goods transported has been dynamically growing (on average by 5.3 percent per year within the last 20 years; DFS, 2005). Thus, the structure of air traffic has been changing, too: Low fare airlines have entered the market once dominated by mostly state-owned airlines, also diverting some traffic from main airports within metropolitan areas to more or less remote regional airports that are often subsidized by local state governments. Due to the difficult economic situation of these regional airports - depending on subsidies and the continuous devotion of few low fare airlines making up the main share of their business - it is hard to predict their future and thus the accurate regional distribution of flights in Germany. Apart from decentralized traffic, the big airports too have seen substantial growth and there have been constant construction works going on at many of them to cope with the increasing competition and volume of flights. In consequence of these structural changes, the following assessment of the regional distribution of risk due to air traffic has to be seen as a temporary snap-shot. The assessment method, however, can be further developed and used for risk updates.

\subsubsection{State of the art of assessment of air traffic risk}

Over the years, there have been common efforts of government authorities, science and the commercial stakeholders of air traffic (aircraft industry, airlines, airports, air traffic controls) to reduce the hazard due to air traffic despite the increase in traffic volume. In Germany, Bundesstelle für Flugunfalluntersuchung (BFU, German Federal Bureau of Aircraft Accidents Investigation) is in charge of collecting data on civil air traffic accidents and the investigation thereof. On the European level, within the conjoint project European Coordination Centre for Aviation Incident Reporting Systems $(\text { ECCAIRS })^{27}$ of the membership countries, a databank system has been developed for the collection and analysis of air traffic accidents. In the US, extensive data on such accidents as well as on near misses is stored in specific databases established by the National Aviation Safety Data Analysis Center (NASDAC) as part of the Federal Aviation Administration ${ }^{28}$.

\footnotetext{
${ }^{26}$ IFR: Flights are operated using the plane's instruments, not only human sight.

${ }^{27}$ Website: http://eccairs-www.jrc.it/Start.asp [20/03/2006].

${ }^{28}$ Aviation Accident and Incident Data System (AIDS), Aviation Safety Reporting System (ASRS), Near Midair Collision System (NMACS). Available via https://www.nasdac.faa.gov [21/12/2005].
} 
Besides the official data collections, several private internet databases offer a reliable service as sources of information on air traffic accidents from all over the globe. These are, inter alia, Aviation Safety Network, PlaneCrashInfo.com, and AirDisaster.com ${ }^{29}$ which contain both statistics of accidents and reports of single crashes. Other institutions collecting and analysing data are aircraft producers like Boeing ${ }^{30}$ who also publish statistics on this topic.

Data are appraised by authorities and the research community. BFU, for example, has been producing and publishing annual reports for Germany containing statistical information on the characteristics of accidents since 1990 (cf. BFU, 2005). Furthermore, they edit special investigation reports on certain severe accidents as well as recommendations for safety improvements which are derived as conclusion from the findings of the investigations. On the scientific side, researchers from various engineering disciplines are investigating the topic, which has resulted, e.g., in the studies of Ladkin (2002), Junge (2003) and Johnson (2006). Besides delivering statistical information like relative frequencies of specific locations, times or segments of flights, the studies reveal findings on the reasons causing the accidents. Findings with respect to technical reasons (cf. Ladkin, 2002) or personal and organisational ones (cf. Junge, 2003), and even regulatory problems (cf. Johnson, 2006), respectively, are expected to be used by the stakeholders of air traffic in order to reduce overall air traffic risk by improving the aspects mentioned above.

For our purposes, i.e. a general risk assessment of German air traffic, some conclusions can be drawn from these sources:

- Most of the accidents happen during certain phases of a flight: Start and early climb (17\%) or final approach and landing (51\%) (cf. Boeing, 2004). They take place at the close environment of an airport including itself - Schmidt-Thomé (2006) mention a distance of maximum $5 \mathrm{~km}$ around airports, however without further evidence. Thompson et al. (2001) who work on the topic of "groundling" fatalities give a more detailed differentiation. Their study suggests a zone of $16 \mathrm{~km}$ radius when considering this type of risk.

- Despite the enormous increase in air traffic, global accident rates have dropped from their peak in the 1970s: Then more than 70 cases of hull losses per year, i.e. aircrafts damaged beyond repair, had to be registered. Since the mid-1990s, this rate has dropped to well below 50 hull loss events each year. According to that

\footnotetext{
${ }^{29}$ Websites: Aviation Safety Network - http://aviation-safety. net/index.shtml; PlaneCrashInfo.com - http://www.planecrashinfo. com/database.htm; AirDisaster.com - http://www.airdisaster.com/ cgi_bin/database.cgi [all 21/12/2005].

${ }^{30}$ Website: http://www.boeing.com/news/techissues/ [21/07/2006].
}

development, there is a trend of decline in the number of fatalities (cf. Ranter, 2004).

- A similar tendency in decrease holds true for the case of Germany, where the number of accidents has diminished continuously from 519 in 1992 to 271 in 2004 (cf. BFU, 2005:5).

Another factor relevant to the assessment and mapping of the air traffic hazard is the distinction between scenarios of airplanes colliding versus sheer crashes of single airplanes. Whereas the former kind of accident affects a large area by scattering smaller parts of the wrecks, single plane accidents lead to a localized but strong impact. Additionally, the degree of the hazard with respect to subsequent fires is connected to the remaining amount of fuel in the tanks and thus to the timing of an accident during the flight.

4.2.2 Data and methods for assessing and mapping the air traffic risk in Germany

Based on the above considerations we decided to model and map the air traffic hazard in the following way: The casualties in Germany since 1990 due to air traffic as published by BFU (2005) are added up resulting in an average number of 178.9 casualties per year. Linked to spatial information an area-related risk of dying or getting injured due to air traffic in Germany can be calculated. It is defined as the probability that an average unprotected person present at a certain location is killed or hurt in an accident resulting from air traffic. The personal risk, therefore, depends on the place (cf. Jonkman et al., 2003:3) or the area where people are living. According to Thompson et al. (2001), 63\% of the fatalities have to be expected within $16 \mathrm{~km}$ around an airport. As there is no data given by this study with respect to casualties, we furthermore assume that the shares of fatalities in- and outside the zone of $16 \mathrm{~km}$ can be equated to the respective share of casualties. The number of casualties is needed to make the information meaningfully comparable to German statistics: The values of fatalities listed by BFU (2005) are not able to reflect the dimension of the hazard very well because of the short period of time in comparison to the variation of fatalities in different years. Taking into account above considerations, two generic zones can be distinguished: Areas close to the 24 German airports handling IFR traffic (generic zone I: buffers of radius of $16 \mathrm{~km}$ ) and areas outside the 16-km-radiuses (zone II). Each buffer covers approximately $804 \mathrm{~km}^{2}$. This leaves an area of about $339000 \mathrm{~km}^{2}$ for generic zone II since the total area of Germany is approximately $357000 \mathrm{~km}^{2}$.

Regarding the hazard outside the airport buffers, we assume that there is the same hazard across all of that area calculated as the number of expected annual casualties outside the buffers (according to above considerations, $37 \%$ of all casualties are expected there) divided by the total area of zone 


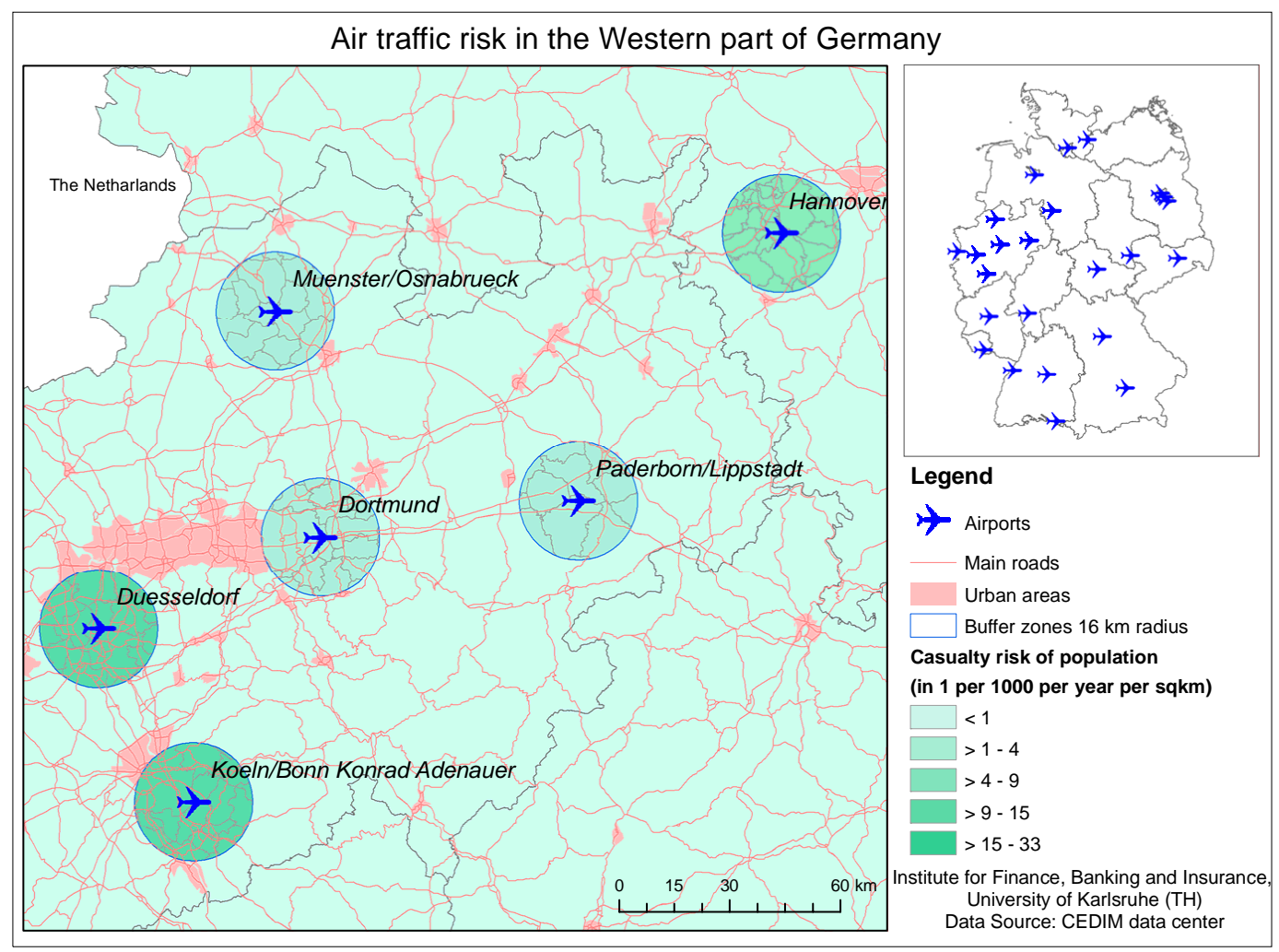

Fig. 7. Air traffic risk (casualties) in the Western part of Germany.

II. For modelling the hazard within the buffer zones, we assume that there is a linear relationship ${ }^{31}$ between the probability of accidents and the amount of traffic. The latter serves as the only determinant for the hazard under investigation: By means of data on IFR flights provided by Arbeitsgemeinschaft Deutscher Verkehrsflughafen (ADV, German Airports Association), we calculate the traffic quota for each airport: The annual number of flights taking place at a certain airport is divided by the annual number of flights of all German airports. In the only case of overlapping buffers (the three airports of Berlin) the numbers of the referring airports are summed up before calculating a conjoint traffic quota. German airports (indexed $i$ in the following formulae) show traffic quotas $t_{i}$ varying from $0.49 \%$ for Lübeck airport up to $22.9 \%$ for the most important German airport at Frankfurt am Main.

The area-specific annualized risk $R(i)$ per $\mathrm{km}^{2}$ within each airport buffer zone $i$ is then calculated as the number of casualties $c$ to be expected per year within all German airport buffer zones divided by the total size of all buffer zone areas $a$ multiplied with the traffic quota:

Risk $R(i)=c / a * t_{i}$

\footnotetext{
${ }^{31}$ This assumption is preliminary and has yet to be substantiated by means of appropriate data.
}

\subsubsection{Results and mapping of the air traffic risk}

The spatial distribution of German airports reveals that they are allotted all over the country (cf. Fig. 7) with the exception of North-eastern Germany where only few airports are located. A concentration above average exists in the denselypopulated Rhine-Ruhr-area. Therefore, the latter seems to be especially endangered by air traffic. Figure 7 shows the map resulting from the modelling above for the area of the federal state of North Rhine-Westphalia and its surroundings in the Western part of Germany (note that, differing from the text, for displaying purposes, values are given in 1 per 1000 in the map).

Regarding the risk values calculated it has to be concluded that the overall risk of casualties stemming from air traffic is low. Compared to the total mortality of 2.42 people in Germany per year and $\mathrm{km}^{2}$ (mortality rate of 0.011 in 2005), the expected annual number of people dying and getting injured due to air traffic is only 2.0E-04 per year when living in generic zone II. This index value, however, can be considerably higher in zone I, especially in close vicinity to very important airports: It amounts to 0.032 for Frankfurt, 0.025 for Munich and 0.014 for Berlin (regarding all its airports). Furthermore, even for small airports the values are significantly higher than for the areas outside the buffer zones, with Lübeck as the smallest airport considered holding one of $6.9 \mathrm{E}-04$ 


\subsubsection{Discussion of the air traffic risk analysis approach}

Again, the chosen methodology for assessment and mapping of air traffic risk has to be subject to discussion. Overall, the indicator of the risk modelled as expected casualties per year and $\mathrm{km}^{2}$ is one that could be easily compared to indicators describing other perils (natural and man-made hazards). The approach for its calculation is, for the hazard part, of statistical nature and does not include any extensive differentiation regarding specific reasons for plane accidents. There is also a lack of data for a detailed modelling of certain accident types like collisions or individual plane crashes.

Regarding hazard and risk, it has to be stated that there is no reliable data for Germany justifying a distinction between those concepts: Vulnerability of people towards air traffic accidents might include quantifiable differences - people who choose to travel with airlines of unequal safety standards, people who live in high rise buildings that might collapse yielding in more casualties per building than average etc. But these assumptions cannot be statistically proven as for now. Furthermore, the detailed reasons causing casualties are not given in any of the accident databases. In German statistics there is not even a distinction between "groundling" casualties and those from people inside the aircrafts. From American experiences, though, "groundling" fatalities are only few percent of all people killed by air traffic accidents (Thompson et al., 2001). That is why we do not model "individual risk" in addition to the area-related risk as defined above. The definition of such an indicator would have many uncertainties: Missing statistical data as well as problems of combining the number of people inside airplanes with their high exposition and vulnerability to crashes to the number of people on the ground of whom only a small share is hit by plane crashes.

There are nearly no numbers let alone any distinctions between different kinds of property damages. We, therefore, cannot include other elements of exposure apart from human beings into our considerations. In order to expand future research to this interesting direction, there is a crucial need for better data.

\subsection{Terrorism and its changing nature}

So far, no consensus has been reached regarding a globally accepted definition of terrorism (OECD, 2003:103). This is partly due to the broad spectrum of actions subsumed under this term in the past, but also to varied perspectives adopted by authorities in different parts of the world. The changing nature of the phenomenon is creating additional problems for the development of concerted counter-strategies.

Terrorist acts can be characterized by their goals, the strategic behaviour demonstrated, the kind of perpetrators, their targets, the way attacks are executed, and the means or weapons used. Whereas the aim of conventional terrorism is to change the politics of governments by dividing them from their citizens through the use of fear (Hoffmann, 1999; Wald- mann, 1998), the motivations seem to have shifted during the recent years. Some terrorist organisations are now attacking Western values and institutions which transpose the threat from the local to the international arena (OECD, 2003:104; Laqueur, 2003).

The corresponding targets and means are nonconventional, too: Apart from seeking to draw attention to their cause, a maximum social disruption is intended, e.g., by attacking critical infrastructure (Apostolakis and Lemon, 2005:361). Another goal, especially of religious-based terrorist groups, consists in causing a number of victims and collateral damage (Bremer, 2002; OECD, 2005:10; Stern, 2003). Weapons used may be conventional, or extended to new technologies like the internet for inflicting physical and economic damage (Arquilla and Ronfeldt, 2001; Sandler and Enders, 2004), for instance via cyber attacks (Nelson et al., 1999). Other scenarios regarded as plausible include the use of deadly chemicals, biological agents, or the dispersal of radioactive and nuclear materials (Kunreuther and Michel-Kerjan, 2005:112). ${ }^{32}$

These deliberate actions are hard to predict, especially since historical data is mostly based on conventional terrorism, which draws from different behavioural patterns (Enders and Sandler, 2000). Moreover, terrorists adapt their strategy according to their knowledge of prevention measures taken by potential targets, the government and public servants (Bremer, 2002). This means that the nature of the risk is continuously evolving. ${ }^{33}$ Thus, hazard and vulnerability form a unity in the case of deliberate actions in terms of terrorism. By the aims of the assaulters, location and timing of a terrorist disaster are intrinsically tied to the attacked vulnerable values, people and assets: The more vulnerable a targeted system, the more attractive it becomes to malicious attacks of all sorts; the larger the loss expected from certain actions, the more likely the scenario would be chosen (Woo, 2002). In the following, exemplary assessments of terrorism risk regarding conventional and non-conventional targets and means are shown.

\subsubsection{Data on international terrorism}

As for any risk mentioned in this paper, an ex post approach of analysing past events also marks the starting-point of the investigation of conventional terrorism. However, it seems difficult to choose suitable reference scenarios of situations that have the potential to induce catastrophic outcomes: In Germany, there have not been many terrorist events in the

\footnotetext{
${ }^{32}$ The borderline between war and terrorism is blurry; for an extensive discussion see, e.g., Laqueur (2003).

${ }^{33}$ Kunreuther and Michel-Kerjan (2005) and Michel-Kerjan (2003) who both published numerous articles on terrorism risk call this "dynamic uncertainty"; they also refer to other characteristics of this kind of hazard such as the interdependent security within interrelated systems - it is the weakest link that determines the safety of all members (Kunreuther and Heal, 2003).
} 
last two decades, so the available basis of data is scarce. Furthermore, past attacks did not show a catastrophic scale. However, the face of terrorism has obviously changed and turned into a global phenomenon with varied characteristics. Therefore, one has to look at events at foreign locations for reference.

Due to the vast amount of terrorist acts happening worldwide, it seems to be very challenging to create an exhaustive, consistent and error-free database on this topic. Indeed, even well known international sources like International Policy Institute for Counter-Terrorism (ICT) ${ }^{34}$ and National Memorial Institute for the Prevention of Terrorism (MIPT) ${ }^{35}$ reveal some weaknesses regarding those criteria.

- The ICT database contains about 1400 selected international terrorist attacks from all over the world that happened since the late 1980's.

- More than just a database, the MIPT Terrorism Knowledge Portal offers information on both terrorist groups (their ideology, history, important members and pictures) and attacks from around the globe dating back to 1968 for international terrorism and to 1997 regarding domestic terrorism (i.e. in the USA).

- Detailed information on aspects shaping the vulnerability of countries all over the world can also be found in the report on Patterns of Global Terrorism, published by the United States Department of State until 2004 (http: //www.state.gov/s/ct/rls/c14818.htm [21/12/2005]).

- Another important source of current information on the topic of terrorism, including a typology of terrorist groups, is compiled by the library of the United States Air Force Air University, which is available online at http://www.au.af.mil/au/aul/bibs/terror05.htm $\backslash \#$ inter [21/12/2005].

\subsubsection{Hazard, exposure and vulnerability analysis approach}

According to our examinations based on the data banks mentioned above and other sources (cf. Sect. 4.3.1), the attacks of global terrorism feature common dominant aims to varying degrees: Killing people, attacking the symbolic values of their enemies and - to a lesser extent - producing economic losses.

Classic targets frequently attacked by shootings or bombings both in Germany and other parts of the world have been military or diplomatic institutions like embassies and their personnel. In contrast, unconventional terrorism has often aimed at various soft targets that are hard to protect. In doing so, terrorists sometimes try to provoke disastrous out-

\footnotetext{
${ }^{34}$ ICT Database for International Terrorist Attacks: http://www. ict.org.il/inter_ter/attacksearch.cfm [21/12/2005].

${ }^{35}$ MIPT Terrorism Knowledge Base: http://www.tkb.org/Home. jsp [21/12/2005].
}

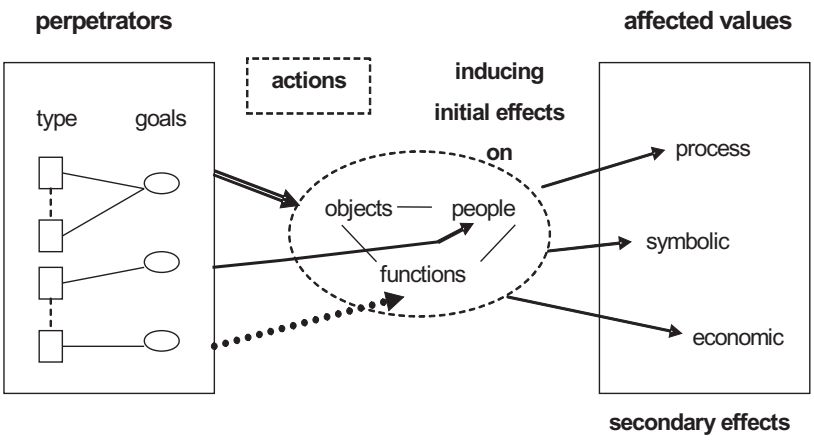

Fig. 8. Modelling vulnerabilities of complex systems.

comes (e.g., 11 September 2001) or mass panics and hysteria by comparably simple means, using humble weapons or sheer threatening. These findings have to be transferred to the context of Germany, its population density, its symbols and economic values, keeping in mind the assumptions regarding the power ${ }^{36}$ of terrorists located there as well as counter-terrorism measures. ${ }^{37}$

The intentional character of this peril requires deliberations taking into account objectives of assaulters for possible future attacks. With the assistance of scenario building experts from engineering and management consulting, we developed an approach to model vulnerabilities of complex systems with respect to malicious actions. This model consists of four interdependent tasks (cf. Fig. 8):

1. setting up a typology of people or groups as possible offenders, and their respective goals; here, we differentiate between offenders with ideological, ethnical, vigilant and religious motivations;

2. generating an inventory of potentially exposed elements (objects, people), and their respective functions;

3. assessing the structural vulnerability of these elements to certain goal-related actions of the perpetrators who intend to produce specific effects;

4. estimating the values affected: This can be done in relation to critical processes (e.g., interruption of life-lines or certain events), or by accounting for symbolic and economic values.

\footnotetext{
${ }^{36}$ Decisive factors whether terrorists pose an acute threat to society are the available means of their endowment concerning affiliated people, money, know-how and logistics (Kunreuther et al., 2003:18). Catastrophe modelling experts from consultancies like Guy Carpenter or Risk Management Solutions (RMS) elaborate on this in theoretically oriented publications (Major, 2002) or with a focus on terrorism risk in the United States (RMS, 2003).

${ }^{37}$ For a compilation of institutions involved in counter-terrorism measures in Germany confer Werner and Lechtenbörger (2004).
} 
Table 4. Index parameters and weighting factors to calculate vulnerability index values $\left(v_{a}\right)$ for each diplomatic mission in Germany.

\begin{tabular}{|c|c|c|c|}
\hline & Parameters & Index & Weight \\
\hline 1 & Population number (million) & $\begin{array}{l}\text { over } 100=1 \\
50 \text { to } 100=0.5 \\
\text { less than } 50=0\end{array}$ & 2 \\
\hline 2 & Membership in G8 & yes $=1$, no $=0$ & 2 \\
\hline 3 & Involvement in the war against Iraq & yes $=1$, no $=0$ & 2 \\
\hline 4 & Membership in NATO & yes $=1$, no $=0$ & 1.5 \\
\hline 5 & Membership in OECD & yes $=1$, no $=0$ & 0.5 \\
\hline 6 & Religious conflict & $\begin{array}{l}\text { number of entries in the } \\
\text { World conflict list }{ }^{1} \\
(1996-2002) \text { : } \\
4 \text { or more }=1 \\
\text { less }=0\end{array}$ & 3 \\
\hline 7 & $\begin{array}{l}\text { Historical information on past attacks on } \\
\text { diplomatic institutions }\end{array}$ & $\begin{array}{l}\text { number of attempts: } \\
4 \text { or more }=1 \text {, } \\
1 \text { to } 3=0.5 \\
\text { and } 0=0 \\
\text { number of wounded/dead: } \\
10 \text { or more }=1 \\
\text { less }=0\end{array}$ & 1 \\
\hline 8 & Economic strength - GDP (billion US\$) & $\begin{array}{l}\text { over } 1000=1 \\
250 \text { to } 1000=0.33 \\
\text { less than } 250=0\end{array}$ & 1.5 \\
\hline
\end{tabular}

1 Available at: http://www.ndcf.org/Conflict_List/World2002/2002Conflictlist.htm [21/12/2005].

Task 3 and 4 co-determine the relative attraction of the endangered system to different kinds of offenders. This leads to the following research questions: How easily can the targeted systems be attacked in order to produce specific effects (structural vulnerability $v_{s}$ )? How attractive are the values they represent to certain perpetrators (attraction $v_{a}$ )?

Assessing the structural vulnerability $v_{s}$ can be a situationspecific task involving extended needs for detailed data that rarely is available to scientists. The structural vulnerability of embassies, e.g., is best addressed by a team of engineering experts from various disciplines. Its analysis, therefore, has to be omitted here. In contrast, we are definitely able to judge the structural vulnerability of sites that share typical characteristics derived from one principal function, like football stadiums. This is achieved by using an approach of exposure analysis that can be generalized and adapted for assessments of other sites that share common functions and, therefore, characteristics. This also applies to analyses of the relative attraction of potentially targeted systems $\left(v_{a}\right)$. The following section contains an outline of our approach within the given framework.

4.3.3 Assessing the vulnerability of embassies in Germany in terms of attraction

Attacks on embassies are representative for the conventional type of terrorism: Malicious actors focus their attention on these institutions because they stand for a country the terrorists are feeling hostile to. The reasons for this antagonism may be manifold - the challenge is to find proxy parameters that reflect this aspect of vulnerability. By using different parameters derived from extended inductive research, a vulnerability index $v_{a}$ can be built which takes into account permanent political characteristics as well as current critical international situations.

Therefore, the population of a country is incorporated in the index as well as its status of membership at G8, NATO or OECD. Another criterion is currently the attendance of the coalition of countries involved in the war against Iraq. Regional conflicts within the territory of a country play another important role in producing terrorist movements and are, therefore, recorded and used for modelling. Economical strength and poverty of the population are further parameters. Moreover, historical information on past attacks on diplomatic institutions of a country and the respective outcomes is collected and incorporated into the model as well.

Obviously, the results of an analysis of terrorist risk can be very short lasting, depending on the change of a political situation. Thus, the method used has to allow for quick adaptation. Additionally, some of the criteria mentioned above seem to induce a focus on certain kinds of terrorism (religious or ideological) at the expense of other forms (e.g., due to ethnic conflicts). We, therefore, assign a case-specific 


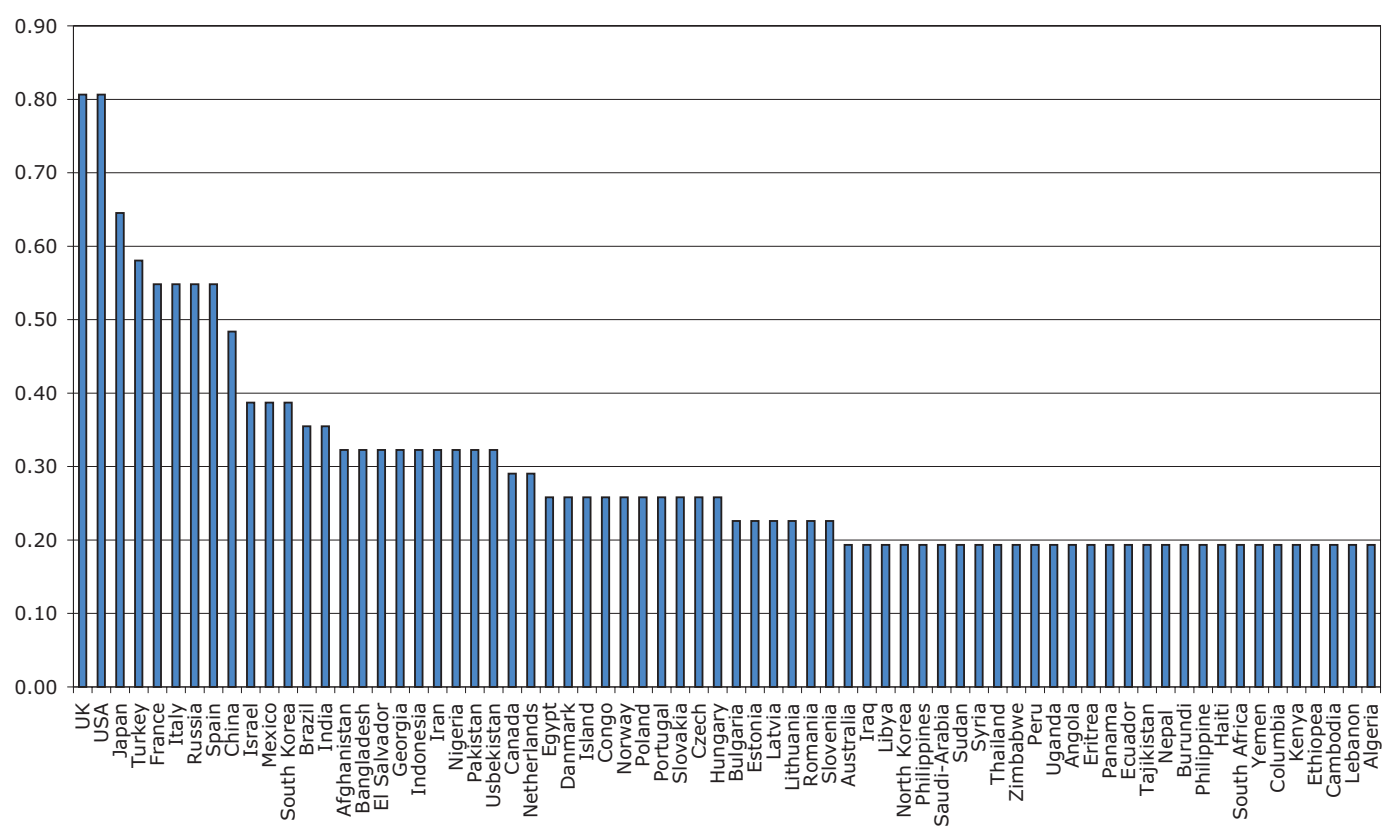

Fig. 9. Index values $\left(v_{a}\right)$ reflecting the attraction of national embassies to terrorism.

weight to each criterion before calculating the vulnerability index; these weight and index parameters are listed in Table 4 .

Figure 9 shows this index in a generalized form. Its stability is tested with each additional terrorist event occurring. Under current conditions, index values of $0.81^{38}$ have been calculated for the United Kingdom and the USA; their embassies, therefore, are regarded as the most endangered ones in Germany.

This attraction consists in its symbolic value to the aggressors, which we measure via political and socio-economic data. It forms the basis of further considerations such as integrating geospatial aspects like the location of the embassies within their host city or country. Other necessary additions for achieving a complete risk assessment are considerations regarding the kind of attack and protective measures taken by the exposed elements and entities responsible for their security, which, as mentioned, is beyond the scope of this study.

\subsubsection{Exposure and vulnerability assessment of football games in stadiums}

\section{Specific characteristics regarding vulnerability}

A terrorist attack at a football game, for instance at the FIFA World Cup 2006 in Germany, is an example for non-conventional terrorism. Many factors contribute to the vulnerability of such an event, in terms of structural

\footnotetext{
${ }^{38}$ The index value of each country is scaled down from 0 to 1 where 1 is the maximum value. This is done by dividing the vulnerability index of a country with the sum of all weights.
}

conditions as well as regarding its attractiveness to potential perpetrators:

- Football is by far the most popular sport in Germany, attracting approximately 400000 spectators every week to the stadiums where the nine games of the 1 . Bundesliga (Premier League) take place, and many more people are following the media coverage thereof. During the World Cup, worldwide attention could be taken for granted, playing to the aims of terrorists who often consider their acts a means of communicating their ideology (cf. Waldmann, 1998).

- Mass rallies by themselves state a considerable hazard to spectators, ${ }^{39}$ especially in the case of stadiums that are sold-out. Infamous aggressive fans of certain teams can play an important role for the hazard within a stadium during the game or outside of the stadium before and after the game, intimidating other spectators and thus setting up a climate where panics might happen.

- As another factor, the Stiftung Warentest (2006), an independent German foundation testing goods and ser-

\footnotetext{
${ }^{39}$ In 1985, 39 spectators died and more then 400 were injured when English and Italian hooligans started to fight each other during a final game in the Heysel Stadium in Brussels. People were killed by others panicking and victims were pressed against the wall until it collapsed. By means of records from 1946 through 2005, it has to be concluded that events of mass panicking and hooliganism lead to substantial casualties in Europe with 670 dead people. Deserving of great thanks, the collection of data was placed to our disposal by the editorial department of German football magazine "kicker".
} 
vices by means of scientific methods, in a recent study denounced deficiencies within German stadiums. These refer to problems of structural safety $\left(v_{s}\right)$. The deficiencies, ranging from minor to considerable for the twelve stadiums selected for hosting the FIFA World Cup 2006, stem from problems of stadium objects usable as weapons, fire safety, escape route problems (escape bottlenecks and orientation), risk of tripping, and congestion pressure (i.e. are there sufficient emergency exits with respect to sell-out spectator capacity?).

Fully booked stadiums have to be expected for international events like the World Cup, and this facilitates the triggering of panics by assaulters. The sites and times of the games are pre-scheduled, with the preliminary round opponents of each game even known half a year in advance thus allowing a strategic planning of attacks. Additionally, economic stakes in football are stunning (cf. Strehl, 2005) and can entail enormous follow-up losses in case of an attack. These losses might be a goal in itself, ${ }^{40}$ at least of terrorists pursuing political and religious motives like Al Quaida.

Research on the vulnerability of stadiums due to terrorist attacks has not been conducted so far, and thus it is not possible to compare our studies with others as it was done for NPP and air traffic. However, in assessing the vulnerability of stadiums used during the FIFA World Cup 2006, we follow state of the art research methodologies that include comprehensive analyses of the exposed elements, careful constructions of scenarios and their rankings.

\section{Data collection for the vulnerability assessment of football games in stadiums}

The research team has, although hindered through nondisclosure of information by both official and private contacts, systematically collected and processed information on the stadiums including their size, building characteristics like emergency installations and exits as well as safety plans, safety management and exercises. In workshops with experts ${ }^{41}$, scenarios for possible attacks have been developed and compared with each other regarding their

\footnotetext{
${ }^{40} \mathrm{Cf}$. the announcement of Osama Bin Laden on 30 October 2004, regarding his motivation to attack the people of the United States of America. The breakdown of capital markets after 11 September 2001 is said to have been intended and partially controlled by him and the World Islamic Front for Jihad against Crusaders and Jews.

${ }^{41}$ Together with Walter Schmitz and Karl Neubauer from Industrieanlagen Betriebsgesellschaft $m b H$ (IABG, Industrial Asset Management Company), a consulting company for defence and security, we conducted a real-time computer-assisted terror game dealing with synchronized attacks on critical infrastructure such as energy and information networks and a football stadium intended to be used during the FIFA World Cup 2006. Workshop-participants included academicians from various disciplines (natural sciences, engineering, economics) and from public authorities. Follow-up
}

possible outcome of losses in terms of money, human life and health, or system functionality.

\section{Exposure analysis}

As a first step for assessing the exposure $v_{s}$, we compiled a list of individual objects within a typical stadium during a football match. The values of these potential objects at risk were appraised by differentiating between asset value, functional value for the continuation of the game as well as for the whole World Cup, and symbolic societal value.

The highest asset value was assigned to the stands and roof; these constructions also carry the highest functional value. The workshop participants also stated high functional values for lighting installation, the grass of the field, and camera plus TV-broadcasting installations. Highest symbolic values were assigned to the stands and roof, furthermore to the Very Important Persons (VIP) and the VIP area, players and referees as well as normal spectators (non-VIP). Additionally, all objects besides toilets, grass of the field, football equipment, camera plus TV-broadcasting installations, and security equipment were assigned a panic factor, which means that the destruction of these objects by a severe attack might have the potential to trigger a panic.

\section{Vulnerability analysis}

As a next step, the relative vulnerability $v_{a}$ of objects and people to attacks occurring before and after as well as during a match was checked. Catering services (before a match), doors and gates (before, during and after a game) as well as camera plus TV-broadcasting installations were assigned the highest vulnerability values. The same applies to regular spectators (not VIP), during and after a match.

\section{Scenario modelling and ranking}

After these preparatory steps, our scenario building framework (described in Sect. 4.3.2) was applied to this context: Depending on each type of perpetrators, a sequence of scenarios for attacks during the FIFA World Cup 2006 was established and arranged according to their relative probability.

Following the typology of Benzin (2005), only few types of assaulters can be expected to attack the series of matches: Those with religious motives or those with an ethnic or nationalistic motivation provided that their teams are listed. During the workshops, varied scenarios of attacks including sheer threat of committing a terrorist act were acted out, and

workshops concentrated on football games in stadiums and their potential endangerment through terrorist acts. We started with onsite inspections of a typical stadium during games, led by insurance specialists, and continued with research group meetings attended by football experts. 
the susceptibility of typical stadium objects and people to distinct forms of attack was investigated.

In this step of the analysis, we also introduced success factors spanning five levels ${ }^{42}$ of potential success on the part of the assaulters. Thereby we distinguished between direct (immediate) damages to objects or people and indirect damages caused by effects following the event like the outbreak of a panic. The probable overall success of terrorists trying to destroy asset, functional and symbolic values was then determined for each form of attack (multiplication of success factors with the index values of the different categories and adding up the results for all targets), so that a ranking of different scenarios could be performed.

\section{Results of the exposure and vulnerability analysis}

Resulting from the scenario ranking, the biggest expected success and, therefore, a high probability of realisation by terrorists acting rationally ${ }^{43}$ was attached to the poisoning of beverages. The scenario modelling included further details such as the attack mode, its timing as well as motivation and kind of aggressions. It was concluded that attacks on the central catering station before the start of a match during the first round of events like the FIFA World Cup 2006 by religiously motivated terrorists (Al Quaida) can trigger panics to the audience which might lead to enormous consequences including a high number of casualties, the stop of the match as well as a temporary discontinuation of the games. Additionally, catering for all remaining matches could be suspended, and the games might need to be relocated to another country inducing considerable economic losses for the original host country.

\section{Discussion of the risk assessment}

This risk assessment done for typical football events in typical football stadiums can, of course, be extended and adapted to the individual characteristics of games and stadiums (regarding the match schedules, the structural layout of particular stadiums, their capacity, etc.) while taking into account the risk management measures provided at these sites.

The method suggested for analyzing terrorist threats involves assessments that are more subjective than the approaches used for accidental risks. However, when elaborated by a group of experts exchanging their views, certain objectivity can be expected through the consensus reached. Since information on possible attacks and offenders is intrinsically scarce, dynamic uncertainty (Kunreuther et al., 2003) will persist and necessitate analytical approaches that are flexible enough to adapt to increasing knowledge about

\footnotetext{
${ }^{42}$ Very high, high, middle, low, and very low.

${ }^{43}$ Neglecting particular countermeasures to be employed by security organisations like the police.
}

the threat or to changing motivations, strategies and means of potential aggressors.

\section{Summary, conclusion and outlook}

Various approaches for assessing and mapping man-made risks in Germany are presented in this paper. We focused on disastrous accidents that have the potential to affect extended geographic areas, and presented models for assessing terrorism as a major hazard originating from deliberate malicious actions.

Following catastrophe modelling, hazard, exposure and vulnerability are explored dependent on the kind of risk under review. The damages considered are restricted, so far, to life and health of potentially affected people. Frequencies for accidental hazards are estimated based on values published by supervisory authorities and statistical observations of our own, including absolute probabilities. For terrorism, the relative probability of events is either judged via rankings of the likelihood of attacks dependent on the attraction of potential targets, or it is derived from considerations regarding hazard characteristics, structural vulnerability and possible scenarios.

NPP constitute a complex man-made hazard of international dimensions. For its analysis, expert knowledge is used and supplemented with observations on aging effects. The assessment has to rely on the only case of a major accident registered so far: Chernobyl, 1986. Therefore, only coarse estimates regarding the vulnerability of the population living nearby are possible. Risk is modelled considering the population density within the area that is certain to be hit severely.

The air traffic hazard is predominantly located at close distance to airports, and statistics seem to back up a decline in recent years on German territory. Due to the lack of other data that might justify a different course of action, we do not further distinguish between exposure and vulnerability with respect to this hazard. Risk is modelled as an area-related phenomenon and measured by the expected value of getting injured or dying within one of the zones around airports or outside of them. Since there are only few incidents with respect to this hazard in Germany, the amount of data is very limited and the numbers available show a great variation over time. Therefore, the statistic-based approach of modelling is rather limited.

Terrorism risk is assessed for conventional and nonconventional threats. Attacks of embassies, though not a recent problem, still constitute a complex hazard of international dimensions. Our modelling is based on assumptions regarding the attraction displayed by embassies as exposed elements. Football events are exemplary for mass rallies and the site- and time-specific threats potentially directed towards them. The approach chosen to analyse this non-conventional risk is extensive: Multiple elements of one object-type are assessed regarding their susceptibility to different kinds of 
attacks within predefined scenarios, and the subsequent likelihood of success (from the viewpoint of terrorists) is judged. This allows a ranking of attack modes and can easily be adapted to specific events or sites and to local risk management practices as well.

Our assessments must be developed, of course:

- Regarding the risk of NPP different distance-related health hazard categories should be integrated in the model - if such information is available from experts in public health. In addition, even though human casualties are of overriding concern regarding accidents in NPP, values of property lost could be included and mapped in order to get a more complete picture of this man-made risk.

- The latter point is also a reasonable extension for improving the assessment of air traffic risk in the buffer zones around airports. Property lost in this case includes air cargo. An improved mapping might be achieved by differentiating between the loss of life, health and property stemming from the aircrafts plus their contents on the one hand, and humans as well as property affected at the ground, on the other hand.

- The assessment approach used for conventional terrorism could be transferred to other objects like specific government or commercial buildings, sites of cultural importance (museums, monuments), etc. - the mapping of "hot spots" in Berlin which can be seen as an agglomeration of buildings attractive to various kinds of assaulters is an upcoming project of the research team. In this case, geographic and other interdependencies between attractive targets have to be included as well.

- However, to achieve a realistic mapping of risks, data is needed about risk management practices. For safety and security reasons, this kind of data is hardly available which impedes a further development of the vulnerability index.

Other data gaps have to be filled, too: For hazards resulting in predominantly local damages general aggregate data has to be completed with regional stocks of exposure. This includes detailed information on asset values, especially industrial and commercial ones, and their geographical distribution. The same holds true for site- and time-specific estimations of people at risk or losses due to interruptions of daily life, particularly business processes, what could be an aim of malevolent assaulters in itself.

With an improved knowledge on the geographical distribution of elements at risk and their characteristics, detailed calculations of potential direct and indirect losses could be carried out.

Our risk-specific analyses might serve as a starting point for integrated risk research and a synoptic mapping with other hazards. This kind of assessment is, e.g., already employed by GRS (2002) regarding the risk of an airplane being directed into a German NPP. ${ }^{44}$

What is needed in addition, are investigations regarding the international comparability and compatibility of statistics, scenarios used, and risk assessments as this affords a valuable foundation for identifying elements at risk and risk management planning - at the national and international level.

Acknowledgements. This work is part of the project "Risk Map Germany" of the Center for Disaster Management and Risk Reduction Technology (http://www.cedim.de), a joint venture between the GeoForschungsZentrum (Research Center for Geosciences) Potsdam (GFZ) and the University of Karlsruhe (TH). We thank the GFZ Potsdam and the University of Karlsruhe (TH) for financial support. Thanks also to E. Basler + Partners Ltd. who assisted us in the development of an approach to model vulnerabilities of complex systems with respect to malicious actions, and to IABG who organized our first workshop regarding exposure and vulnerability assessment of football games in stadiums. U. Kastrup, then from Forschungsstelle für Sicherheitspolitik (Center for Security Studies) at the Swiss Federal Institute of Technology Zurich, Mark Hailwood of Landesanstalt für Umwelt, Messungen und Naturschutz, (Regional Office for Environment, Measurement and Conservation) Baden-Württemberg and A. Strehl of Caninenberg $\&$ Schouten $\mathrm{GmbH}$ gave further helpful hints for man-made risk assessment.

Edited by: A. Thieken

Reviewed by: three referees

\section{References}

Abler, F. and Richardson, D.: Geographic Management Systems for Homeland Security, in: The geographical dimension of terrorism, edited by: Cutter, S. L., Richardson, D. B., and Wilbanks, T. J., New York and London, 117-124, 2003.

Apostolakis, G. E. and Lemon, D. M.: A screening methodology for the identification and ranking of infrastructure vulnerabilites due to terrorism, Risk Analysis, 25/2, 361-376, 2005.

Arquilla, J. and Ronfeldt, D. (Ed.): Networks and netwars: The future of terror, crime, and militancy, Santa Monica, 2001, downloadable at http://www.rand.org/pubs/monograph_reports/ MR1382/index.html [21/03/2006].

Balmforth, H., McManus, H., and Fowler, A.: Assessment and management of 'at risk' populations using a novel GIS based UK population database tool, Safety and Security Engineering, WIT Transactions on The Built Environment, vol. 82, 2005, downloadable at http://www.witpress.com [21/12/2005].

Bedford, T. and Cooke, R. M.: Probabilistic Risk Analysis: Foundations and Methods, Cambridge University Press, New York, 2001

\footnotetext{
${ }^{44}$ Five reference plants with 3 types of ex ante risk control measures regarding the construction of the plant are confronted with 9 damage scenarios. Expected consequences are described as "controllable" or "uncertain", with further qualifications. Cf. http: //www.bund.net/lab/reddot2/pdf/grs_gutachten.pdf [21/12/2005].
} 
Benzin, A.: Versicherungstechnische Bewertung unterschiedlicher Deckungskonzepte für Terrorismusrisiken, Karlsruhe, 2005.

Berg, H. P.: PSA Guidance for the Comprehensive Review of Nuclear Power Plants. Slides of the presentation, 4. Bieleschweig Workshop "Systems Engineering": RisikoAnalyse und Unfall-Ursachen-Analyse, Braunschweig, 2004, downloadable at http://rzv113.rz.tu-bs.de/Bieleschweig/pdfB4/ Bieleschweig4_Folien_Berg.pdf [17/07/2006].

BFU (Bundesstelle für Flugunfalluntersuchung): Jahresbericht 2004 - Unfälle und schwere Störungen beim Betrieb ziviler Luftfahrzeuge (ausgenommen Luftsportgeräte), Braunschweig, 2005, downloadable at http://www.bfu-web.de/ cln_001/nn_41550/DE/Publikationen/Statistiken/Berichte/ BFU_20Jahresbericht_202004, templateId=raw,property= publicationFile.pdf/BFU $\backslash \%$ 20Jahresbericht $\backslash \% 202004$.pdf [21/12/2005].

BMU (Bundesministerium für Umwelt, Naturschutz und Reaktorsichterheit) (Ed.): Maßnahmenkatalog - Übersicht über Maßnahmen zur Verringerung der Strahlenexposition nach Ereignissen mit nicht unerheblichen radiologischen Auswirkungen, Bonn, 2001.

Boeing: Statistical Summary of Commercial Jet Airplane Accidents - Wordwide Operations 1959-2003, Seattle, 2004.

Bremer, P. L.: Assessing the terrorism risk, in: The terror risk: Can it be managed?, edited by: Guy Carpenter \& Company, Inc., pp. 5-10, 2002, downloadable at http://www.plusweb.org/Downloads/Events/ Terrorism-CanItBeManaged-Guy $\backslash \%$ 20Carpenter.pdf [21/03/2006].

BVA (Bundesverwaltungsamt): Neue Strategie zum Schutz der Bevölkerung in Deutschland, edited by: the Zentralstelle für Zivilschutz, Bonn-Bad Godesberg, 2003.

Clark, K.: The Use of Computer Modeling in Estimating and Managing Future Catastrophe Losses, The Geneva Papers on Risk and Insurance, 27, 181-195, 2002.

DFS (Deutsche Flugsicherung): Air traffic statistics - Annual summary 2004, Langen, 2005.

Enders, W. and Sandler, T.: Is transnational terrorism becoming more threatening?, Journal of Conflict Resolution, 44/83, 307332,2000 .

EEA (European Environment Agency): Mapping the impacts of recent natural disasters and technological accidents in Europe, Environmental Issue Report no. 35, Copenhagen, 2003, downloadable at http://www.eea.europa.eu [21/03/2006].

Greenpeace: Alt - älter - Super-Gau? Hamburg, 1998.

Grossi, P., Kunreuther, H., and Windeler, D.: An introduction to Catastrophe Models and Insurance, in: Catastrophe Modeling: A new approach to managing risk, edited by: Grossi, P. and Kunreuther, H., New York, 23-42, 2005.

GRS (Gesellschaft für Anlagen und Reaktorsicherheit mbH): Zusammenfassung der GRS-Studie durch das Bundesministerium für Umwelt, Naturschutz und Reaktorsicherheit (BMU), 2002, downloadable at http://www.bund.net/lab/reddot2/pdf/grs gutachten.pdf [21/03/2006].

GRS (Gesellschaft für Anlagen und Reaktorsicherheit mbH) (Ed.): Annual Report 2004/2005, Köln, 2005, downloadable at http://www.grs.de/en/products/data/3/pe_534_20_3_ jahresb2005.pdf [21/12/2005].

Haimes, Y. Y.: Risk modeling. Assessment and management, New
York, 1998.

Hohmeyer, O.: The Social Costs of Electricity Generation - Wind and Photovoltaic Versus Fossil and Nuclear Energy. The Results of a Study on West Germany and Their Possible Implications for Developing Countries, in: Solar Energy Technology Dissemination, edited by: Gocht, W., Knecht, K., Schleich, B., and Diederich, F., Baden-Baden, 197-218, 1989.

Hoffmann, B.: Inside terrorism, New York, 1999.

Hovden, J.: Public policy and administration in a vulnerable society: regulatory reforms initiated by a Norwegian commission, J. Risk Res., 7(6), 629-641, 2004.

INFAS Geodaten GmbH: Das Data Wherehouse, Bonn, December 2001.

IRSN (Institut de radioprotection et du et de sûreté nucléaire): Incorporating Aging effects into PSA applications - IRSN contribution into JRC Network on Incorporating Aging Effects into Probabilistic Safety Assessment (APSA), Clamart/Fontenayaux-Roses, 2005.

Johnson, C. W.: Linate and Überlingen - Understanding the role that public policy plays in the failure of air traffic management systems, in: Proceedings of the International Workshop on Complex Network and Infrastructure Protection CNIP'06, edited by: Balducelli, C. and Bologna, S., Rome, 508-519, 2006.

Jonkman, S. N., von Gelder, P. H., and Vrijling, J. K.: An overview of quantitative risk measures for loss of life and economic damage, J. Hazard. Mater., 99(1), 1-30, 2003.

Junge, C.: Validierung der Fehleranalysemethode „Why-Because Analysis“ am Beispiel der Midair-Collision in der Nähe von Überlingen am 01. Juli 2002, Gelsenkirchen, 2003, downloadable at http://www.rvs.uni-bielefeld.de/Bieleschweig/third/ Junge-Uberlingen-Dipl.pdf [21/07/2006].

Kaplan, S., Haimes, Y. Y., and Garrick, B. J.: Fitting hierarchical holograpic modeling (HHM) into the theory of scenario structuring and a refinement to the quantitative definition of risk, Risk Analysis, 231/5, 807-819, 2001.

Kleist, L., Thieken, A. H., Müller, M., Seifert, I., Borst, D., and Werner, U.: Estimation of the regional stock of residential buildings as a basis for comparative risk assessment for Germany, Nat. Hazards Earth Syst. Sci., 6, 541-552, 2006, http://www.nat-hazards-earth-syst-sci.net/6/541/2006/.

Klinke, A. and Renn, O.: Systemic risks as challenge for policy making in risk governance, Forum Qualitative Social Research (FQS) 7/1, art. 33, 2006, downloadable at http://www. qualitative-research.net/fqs/ [17/07/2006].

Koelzer, W.: Lexikon zur Kernenergie, Karlsruhe, 2005.

Kromp, W., Andreev, I., Gohla, H., Hittenberger, M., Hofer, P., Kromp-Kolb, H., Rehm, W., Seibert, P., and Wotawa, G.: Riskmap demo-version on CD-ROM, Wien, 1999.

Kunreuther, H. and Heal, G.: Interdependent security, J. Risk Uncertainty, 26, 2/3, 231-249, 2003.

Kunreuther, H., Michel-Kerjan, E., and Porter, B.: Assessing, Managing and Financing Extreme Events: Dealing with terrorism, Working Paper 10179, National Bureau of Economic Research, Cambridge, MA, 2003.

Kunreuther, H. and Michel-Kerjan, E.: Insurability of (mega)terrorism risk: Challenges and perspectives, in OECD: Policy issues in insurance, no. 9, 107-148, Paris, 2005.

Kunreuther, H., Michel-Kerjan, E., and Porter, B.: Extending Catastrophe Modeling to Terrorism, in: Catastrophe Modeling: A new 
approach to managing risk, edited by: Grossi, P. and Kunreuther, H., New York, 209-231, 2005.

Ladkin, P. B.: ACAS and the South German Midair Collision, slides of the presentation, 1. Bieleschweig Workshop "Systems Engineering": Root Cause Analysis and Risk Analysis, Bielefeld, 2002, downloadable at http://www.tu-braunschweig.de/ ifev/veranstaltungen/-bieleschweig/bieleschweig1 [21/12/2005].

Laqueur, W.: No end to war: Terrorism in the twenty-first century, New York, 2003.

Major, J.: Advanced techniques for modeling terrorism risk, paper delivered at the National Bureau of Economic Research Insurance Group conference, 2002, downloadable at http://www.guycarp.com/portal/extranet/pdf/major_terrorism. pdf?vid=1 [21/03/2006].

Mechler, R.: Natural Disaster Risk Management and Financing Disaster Losses in Developing Countries, Karlsruhe, 2004.

Michel-Kerjan, E.: Large-scale terrorism: Risk sharing and public policy, Revue d'Economie Politique, 113/5, 625-648, 2003.

Müller, S., Brauner, C., Grote, G., and Künzler, C.: Safety Culture a reflection of risk awareness, edited by: Swiss Re, Zurich, 1998.

Müller, M., Vorogushyn, S., Maier, P., Thieken, A. H., Petrow, Th., Kron, A., Büchele, B., and Wächter, J.: "CEDIM Risk Explorer" - A Map Server Solution in the Project "Risk Map Germany", Nat. Hazards Earth Syst. Sci., 6, 711-720, 2006, http://www.nat-hazards-earth-syst-sci.net/6/711/2006/.

Nelson, B., Choi, R., Iacobucci, M., Mitchell, M. and Gagnon, G.: Cyberterror. Prospects and implications, White Paper, edited by: Center for the Study of Terrorism and Irregular Warfare, Monterey, CA, 1999, downloadable at http://www.nps.navy.mil/ctiw/ files/Cyberterror $\backslash \% 20$ Prospects $\backslash \% 20$ and $\backslash \% 20$ Implications.pdf [21/03/2006].

OECD: Emerging systemic risks in the 21th century, Paris, 2003, downloadable at http://www.unisdr.org/eng/library/Literature/ 7754.pdf [20/03/2006].

OECD: Terrorism risk insurance in OECD countries, Policy issues in insurance, no. 9, Paris, 2005.

Ottinger, R. L., Wooley, D. R., Robinson, N. A., Hodas, D. R., Babb, S. E. Babb, Buchanan, S. C., Chernick, P. L., Caverhill, E., Krupnick, A., Harrington, W., Radin, S., and Fritsche, U.: Environmental Costs of Electricity, Pace University Center for Environmental and Legal Studies, New York, NY, 1990.

Ranter, H.: Airliner Accident Statistics 2003 - Statistical summary of fatal multi-engine airliner accidents in 2003, 2004, downloadable at the website of the Aviation Safety Network, http: //aviation-safety.net/index.shtml [27/10/2006]

Renn, O.: Risk Governance. Towards an integrative approach, White Paper no. 1, edited by: International Risk Governance Council, Geneva, 2005.

RMS (Risk Management Solutions Inc.): Managing Terrorism Risk, RMS Brochure, California, 2003, available at http://www.rms.com/publications/terrorism_risk_modeling.pdf [21/07/2006].

RSK (Reaktorsicherheits-Kommission) (Ed.): Beherrschung von Alterungsprozessen in Kernkraftwerken, RSK-Empfehlung, Bonn, 2004, downloadable at http://www.rskonline.de/ Download/Leitlinien/EMPF-AltManagement.pdf [21/12/2005].

Sandler, T. and Enders, W.: An economic perspective on transnational terrorism, European Journal of Political Economy, 20(2), 301-316, June 2004.
Schmidt-Thomé, P. (Ed.): The spatial effects and management of natural and technological hazards in Europe, ESPON 1.3.1., 2006, downloadable at the ESPON website, http://www.espon.eu/mmp/online/website/content/projects/ 259/655/index_EN.html [17/07/2006].

Sinha, R. and Goyal, A.: Seismic Risk Scenario for Mumbai, Disasters and Society - From Hazard Assessment to Risk Reduction, in: Proceedings of the International Conference at Karlsruhe, July 26-27, 2004, edited by: Malzahn, D. and Plapp, T., 107-114, Berlin, 2004.

Smith, C. L., Shah, V. N., Kao, T., and Apostolakis, G.: Incorporating aging effects into Probabilistic Risk Assessment - a feasibility study utilizing Reliability Physics Models, NUREG/CR5632, US NRC, 2001.

Sorensen, J. N.: Safety culture: a survey of the state-of-the-art, Reliability Engineering \& System Safety, 76/2, 189-204, 2002.

Starr, C.: Social Benefit versus Technological Risk, Science, 165, 1232-1238, 1969.

Stern, J.: Terror in the name of God: Why religious militants kill, New York, 2003.

Stiftung Warentest (Ed.): Viermal die rote Karte, in: test 2/2006, 78-84, Berlin, 2006.

Strehl, Alexander: Versicherung als Risk Management Tool bei Profifußballvereinen, Karlsruhe, 2005.

Thieken, A. H., Müller, M., Kleist, L., Seifert, I., Borst, D., and Werner, U.: Regionalisation of asset values for risk analyses, Nat. Hazards Earth Syst. Sci., 6, 167-78, 2006, http://www.nat-hazards-earth-syst-sci.net/6/167/2006/.

Thompson, K. M., Rabouw, R. F., and Cooke, R. M.: The Risk of Groundling Fatalities from Unintentional Airplane Crashes, Risk Analysis, 21/6, 1025-1037, 2001.

UN/ISDR (Inter-Agency Secretariat of the International Strategy for Disaster Reduction): Living with Risk. A global review of disaster reduction initiatives, 2004 version, Geneva, 2004, downloadable at http://www.unisdr.org/eng/about_isdr/ bd-lwr-2004-eng.htm [21/03/2006].

US NRC (United States Nuclear Regulatory Commission) (Ed.): Severe Accident Risks - An Assessment for Five U.S. Nuclear Power Plants, Final Summary Report, NUREG-1150, Washington, D.C., 1990.

Vesely, V., Kurth, R., and Scalzo, S.: Evaluations of Core Melt Frequency Effects due to Component Aging and Maintenance, NUREG/CR-5510, US Nuclear Regulatory Commission, Rockville, 1990.

Waldmann, P.: Terrorismus - Provokation der Macht, München, 1998.

WBGU (Wissenschaftlicher Beirat der Bundesregierung Globale Umweltveränderungen): World in transition. Strategies for managing global environmental risks, Annual Report 1998, Berlin, 2000.

Weil, L.: Charakterisierung der Risiken der Kernenergienutzung, Aachen, 2003.

Werner, U. and Lechtenbörger, C.: Phänomen Terrorismus. Die institutionelle Bearbeitung dieser Bedrohung in Deutschland, Homeland Security, 1-2004, 16-22, 2004.

Woo, G.: Quantifying insurance terrorism risk, in: Alternative Risk Strategies, edited by: Lane, M., 301-317, London, 2002. 